Part of Journal of Research of the National Bureau of Standards, Volume 22, May 1939

\title{
AN ABSOLUTE DETERMINATION OF THE AMPERE, USING IMPROVED COILS
}

\author{
By Harvey L. Curtis, Roger W. Curtis, and Charles L. Critchfield
}

\section{ABSTRACT}

The absolute value of a current has been measured by the current balance, using improved coils. The previous work had shown that improvements in the coils were required in order to make them fulfill more nearly the conditions assumed in developing the equations for computing the absolute value of a current from the force measured by the current balance. These new coils consisted of one moving coil made in the form of a short solenoid and one moving coil and one pair of fixed coils wound from anodized aluminum ribbon in the form of a flat spiral.

The results obtained with various combinations of these new coils and one pair of the old fixed coils are consistent among themselves, and their weighted average can be expressed as

\section{NBS international ampere $=0.99986$ absolute ampere.}

This result differs appreciably from that obtained in the preceding work, but it is felt that this new value is more reliable because of the improved coils which were used and the greater consistency of the results.

\section{CONTENTS}

I. Introduction

II. Modifications of the current balance

1. The weights for the balance._.

2. The improved coils

(a) Solenoidal moving coil _...

(b) Moving coil of aluminum ribbon

(c) Fixed coils of aluminum ribbon

III. Measurement of the dimensions of the coils

1. Diameters of the coils

2. Axial widths of the windings

3. Radial depths of the windings

IV. Electric circuit of the current balance

1. Adjustment of the current.

2. The storage battery

3 . Reversal of the current in the fixed coils of aluminum ribbon

4. Insulation resistance...

V. Computation of the maximum force for unit current

1. Maximum force between circular filaments..... 499

2. Maximum force between coaxial coils

VI. Ratio of the radii of the coils

1. Temperature and load coefficients of the coils

2. Length of the magnet.

3. Effect of the cross-sectional dimensions of the coils

4. Results .... 
VII. Experimental determination of the maximum force between the coils_ 504

1. Sources of error and corrections.

(a) Acceleration of gravity

(b) Temperature of the coils

(c) Electrical load on the coils ................... 505

(d) Effect of errors in the measurement of the cross sections of the coils

(e) Summary of estimated accidental errors in determining the absolute value of the current.

VIII. Value of a current in NBS international amperes and in absolute amperes.......

IX. Discussion of results

X. Comparison with results recently obtained in other laboratories.... 511

XI. Appendix I. An addition to the derivation of the force formula to include some terms of the sixth degree in the coil dimensions (by Chester Snow)

XII. Appendix II. Correction to the force caused by an axial displacement of some of the turns in the coils made from aluminum ribbon (by Chester Snow)

\section{INTRODUCTION}

An investigation to determine the absolute value of the international ampere has been in progress at the National Bureau of Standards for more than a decade. This paper reports the progress that has been made, since the previous publication, ${ }^{1}$ by the use of improved coils in the Rayleigh current balance. A description is given of the improvements in apparatus and methods that have been made, and the results obtained by using these developments are recorded. An effort has been made to have this paper so complete that the reader can understand the purpose of all the changes in apparatus and methods that have been used in the recent measurements. However, he will need to consult the previous paper for a description of many of the details of the apparatus which have not been changed.

The method consisted in determining the ratio of the value of a current in absolute amperes to that of the same current in NBS international amperes. The value in NBS international amperes was determined by comparing the electromotive force of a standard cell with a drop in potential produced by the current in a known resistance. The value in absolute amperes was determined in the current balance from the electromagnetic force between parts of a circuit which carried the current. The electromagnetic force was exerted between the current in a moving coil and that in a pair of fixed coils. The coils were coaxial and their planes horizontal, and the moving coil was midway between the two fixed coils. The moving coil was hung from the arm of a balance and the electromagnetic force compared directly with the gravitational force on a known mass. The vertical distance between the moving coil and each fixed coil was adjusted until the electromagnetic force for a constant current was a maximum. In this position, the current in absolute amperes can be computed from the measured force, the number of turns in each coil, and the ratios of the radius of the moving coil to that of each fixed coil. The formula for this computation includes some correction terms which depend on the ratios of the dimensions of the cross section of each coil to its radius.

1 Curtis and Curtis, An absolute determination of the ampere, BS J. Research 12, 665 (1934) RP685. Throughout the present paper statements regarding "the previous paper." "the previous publication," etc. relate to this reference. This previous work was based on the work of Rosa, Dorsey, and Miller, Bul. BS 8, 269 (1911) S171, which will be referred to as the older or earlier work. 
In the previous publication the statement is made that "the most obvious improvement in the current balance is the construction of new coils, the cross sections of which can be more accurately measured and the windings of which conform more nearly to the conditions assumed in deriving the equation for the force." The present paper describes such coils as were then projected. Two new moving coils were first made and were used in the current balance with the two pairs of fixed coils previously described. ${ }^{2}$ Two new fixed coils were then made for use with each of the new moving coils. In the present paper all of these new moving and fixed coils are described, the modifications required by their use are discussed, and the results obtained with them are given.

\section{MODIFICATIONS OF THE CURRENT BALANCE}

The principal modification of the current balance ${ }^{3}$ consisted in the use of new coils of improved construction. Also, arrangements were made to keep the humidity continuously below 40 percent in summer, both in the weighing room and in the observation room.

\section{THE WEIGHTS FOR THE BALANCE}

New calibrated weights and new counterweights were used. A separate cylindrical weight of platinum-iridium was made and calibrated for measuring each of the different electromagnetic forces, so that for each combination of coils as many weights were required as the number of different currents used with that combination of coils. Also, new counterweights were prepared for each of the new moving coils. Each of these counterweights had the same density as the coil with which it was used, so that the buoyancy of the air was the same for the counterweights as for the moving coil. Hence, changes in barometric pressure did not change the rest point of the balance.

\section{THE IMPROVED COILS}

One of the improved moving coils was wound with round copper wire in the form of a single-layer solenoid. The other moving coil and both of the improved fixed coils were wound with aluminum ribbon in the form of a flat, compact spiral. The dimensions of each of these coils could be measured with sufficient accuracy so that errors from this source would in no case introduce into the absolute value of the current an uncertainty of more than a few parts in a million. All of the materials used in these coils were tested magnetically to insure that no error was introduced by their magnetic susceptibility. As the construction of these coils involved several new features, a careful description of the methods used will be given.

(a) SOLENOIDAL MOVING COIL

The solenoidal moving coil (designated P1) was constructed by winding copper wire in a helical groove ground in the outer surface of

The results obtained with these coils are given in a report to the International Committee on Weights and Measures. See Rapport supplémentaire sur la détermination absolue de l'ampére par $M M$. Harvey $L$. Curtis, Roger W. Curtis. et Charles L. Critchfield. Procès-Verbaux des Séances du Comité International des Poids et Mesures [2] 18, 149 (1937). The values there reported are, for the same coils, slightly different in some cases from those which are given in this report. The differences are largely the result of an improved determination of the temperature coefficient of expansion of one of the coils.

In the previous publication are shown a drawing (fig. 1) and a photograph (fig. 2) of the current balance. 
a short glass cylinder. This coil, mounted in the current balance with fixed coils L3 and L4, is shown in figure 1. The thread was ground and lapped in the form by the method developed by Moon." The pitch of the thread was $0.65 \mathrm{~mm}$. The profile of the finished thread is shown in figure 2 as a sinusoidal line between the white and black areas. Disks of various diameters were placed on this profile, as shown in the figure, to determine the size of wire which should be used in winding the solenoid. The wire chosen, corresponding to the disk at the left, had a diameter of $0.51 \mathrm{~mm}$, which was large enough to insure that the wire rested on the sides of the groove and could not touch the bottom, yet was small enough so that adjacent turns could not touch one another. Commercial wire having a diameter of $0.57 \mathrm{~mm}$ was drawn through two dies to reduce it to $0.51 \mathrm{~mm}$. For the second drawing, the wire passed from the die directly to the glass form, with the result that the tension on the wire when wound on the coil was equal to the force (about $3 \mathrm{~kg}$ ) required to draw the wire through the die. The constants of the coil are given in table 1 .

In order to test the uniformity of the windings and to provide polished spots for use in measuring the pitch, a fine, flat oilstone was rubbed axially against the outer surface of the completed winding at eight equally spaced azimuths. This produced eight small elliptical spots on each turn of the wire. The uniformity of the spots showed that the variation in the outside diameter from one wire to the next did not exceed a few tenths of a mircon $(\mu)$.

On each spot were ruled ${ }^{5}$ two lines parallel to the axis of the wire. These lines were used in measuring the axial length from which the pitch of the winding was obtained.

TABLE 1.-Constants of the solenoidal moving coil, $\mathrm{P} 1$, at $22^{\circ} C$

\begin{tabular}{|c|c|c|c|}
\hline Quantity & Measured value & Quantity & Measured value \\
\hline $\begin{array}{l}\text { A verage outside diameter } \\
\text { Diameter of wire } \\
\text { Mean diameter } \\
\text { Number of turns } \\
\text { Axial width of winding } \\
\text { Thickness of form } \\
\text { Length of form } \\
\text { Weight of completed coil } \\
\text { Resistance of winding }\end{array}$ & $\begin{array}{l}24.5121 \mathrm{~cm} . \\
0.0512 \mathrm{~cm} . \\
24.4609 \mathrm{~cm} . \\
41 . \\
2.6650 \mathrm{~cm} . \\
1.1 \mathrm{~cm} . \\
3.6 \mathrm{~cm} . \\
700 \mathrm{~g} . \\
2.75 \mathrm{ohms} .\end{array}$ & $\begin{array}{l}\text { Conicality-difference between di- } \\
\text { ameters at bottom and top.-.- } \\
\text { Ellipticity-difference between } \\
\text { maximum and minimum di- } \\
\text { ameters............. } \\
\text { Temperature coefficient of expan- } \\
\text { sion of outside diameter of com- } \\
\text { pleted coil }\end{array}$ & $\begin{array}{l}0.0001 \mathrm{~cm} . \\
0.0016 \mathrm{~cm} . \\
4.1 \times 10^{-8} /{ }^{\circ} \mathrm{C} \text {. }\end{array}$ \\
\hline
\end{tabular}

The ends of the winding were held by hooks which extended through radial holes near the ends of the form and which were drawn against the wire by nuts on their shanks. The mechanical fastening at each end was several centimeters beyond the places at which the electrical leads were attached.

The electrical leads were attached to the last turn at each end. This method of attachment is shown in figure 3 and is described in the legend of this figure. The leads which connected the winding of the coil to the twisted leads were called the permanent leads of the coil. The permanent leads were at right angles to the windings of the coil itself, so that no vertical force was exerted on these leads by the windings of the fixed coils. The exceedingly small force between

\footnotetext{
- See Curtis, Moon, and Sparks, A determination of the absolute ohm, using an improved self inductor, J. Research NBS 21, 375 (1938) RP1137. The method is described on p. 378.

6 The method of ruling these lines is described on p. 381 of the reference given in fcotnote 4.
} 


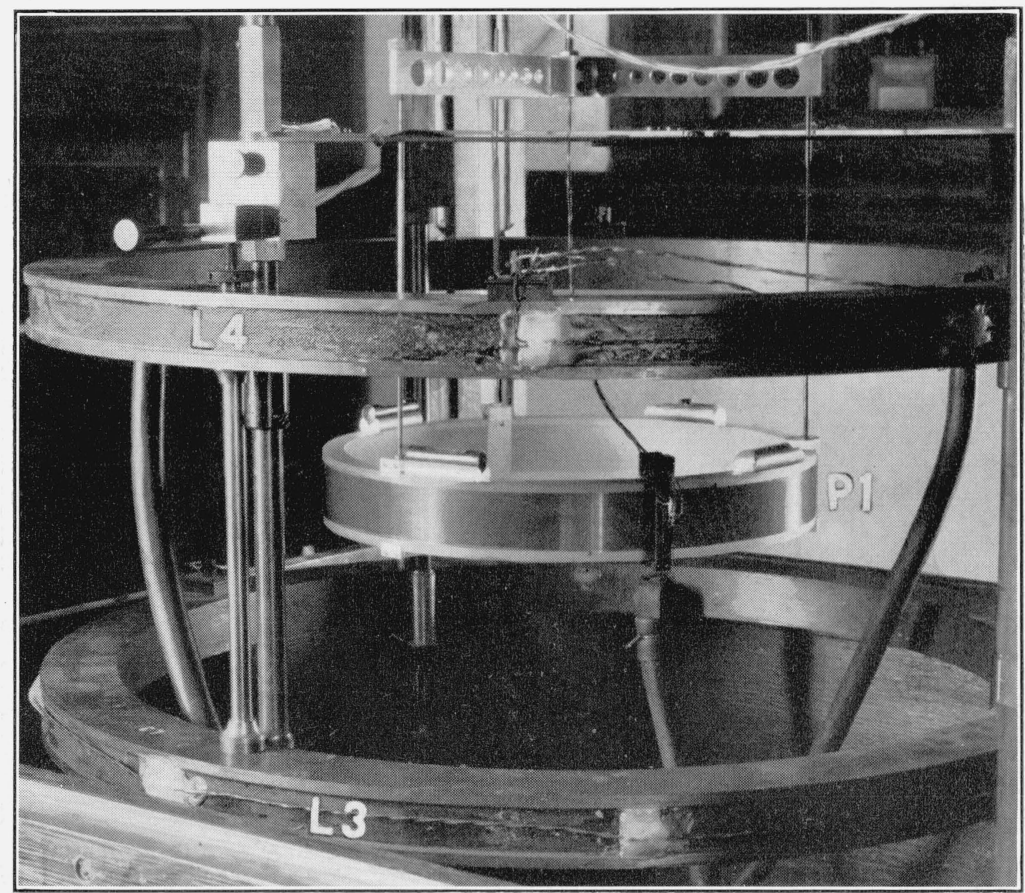

Figure 1.-Solenoidal moving coil, P1, mounted in the current balance between the fixed coils, L3 and L4.

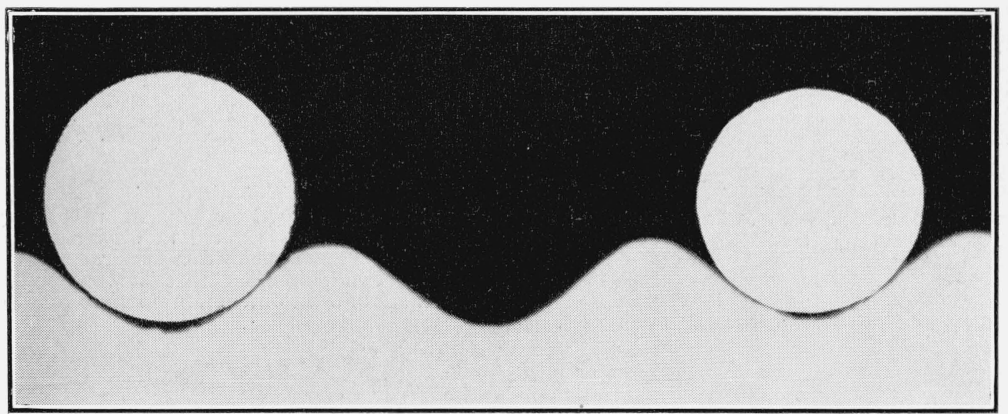

Figure 2.-Profile of the form of the solenoidal coils with disks placed in the threads to represent the cross sections of wires.

The disk at the left represents the size of wire actually used; the disk at the right represents a wire that was too small. The criterion for size was that the wire should make contact with the sides of the groove and should not touch the bottom, and that there be a space of more than $0.1 \mathrm{~mm}$ between adjacent turns. Magnification $\times 50$. 


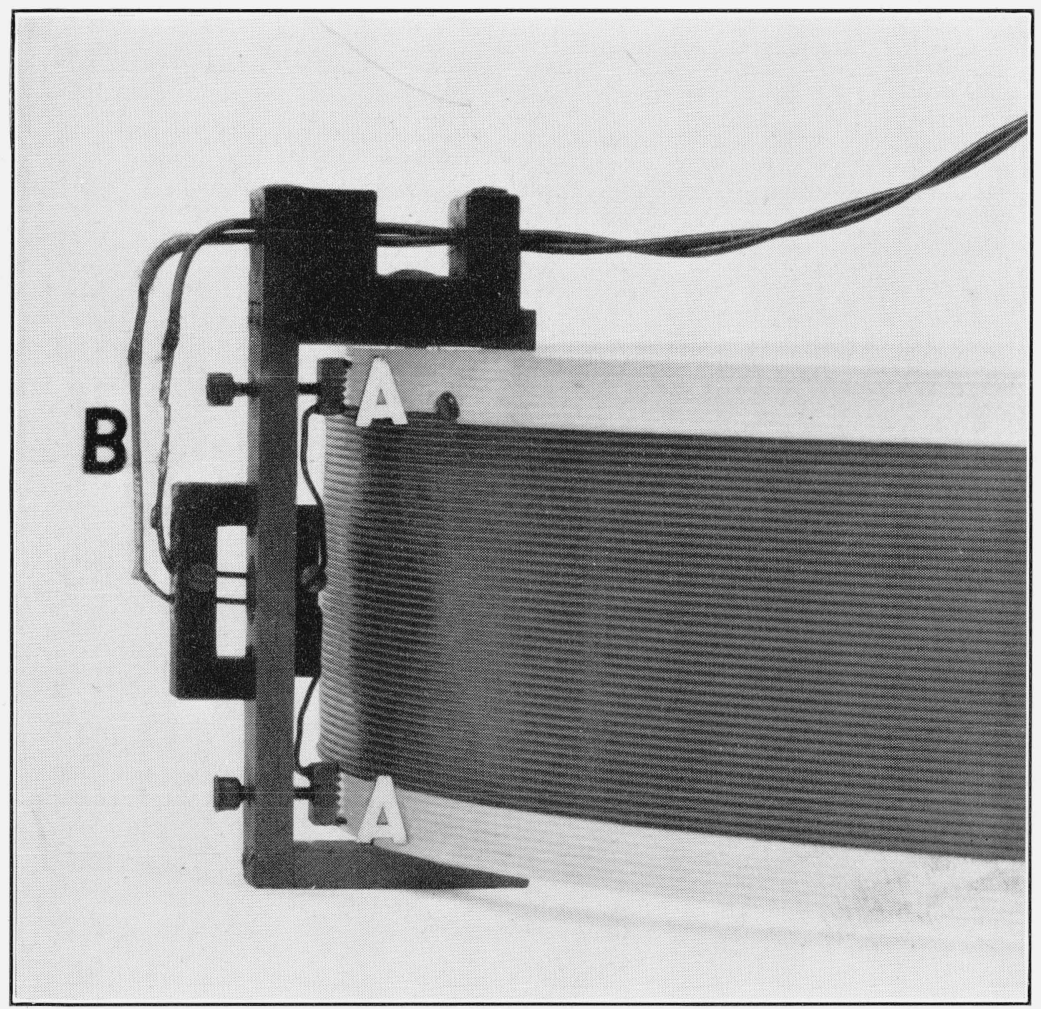

FIgURE 3.-The terminal of the solenoidal moving coil.

The brass contact pieces, $A$, were threaded with the same pitch as the glass form. Each touched only the outside wire of the winding and was pressed against the wire by the screw through the hard-rubber bushing in the brass clamp that surrounded the glass form. The permanent leads were soldered to the brass blocks and extended through the middle of the clamp. When making the lead correction, the lead neare the coil was unsoldered from its permanent lead at the point $B$ and the outer end connected to the other lead by a drop of solder. Magnification X1.5. 


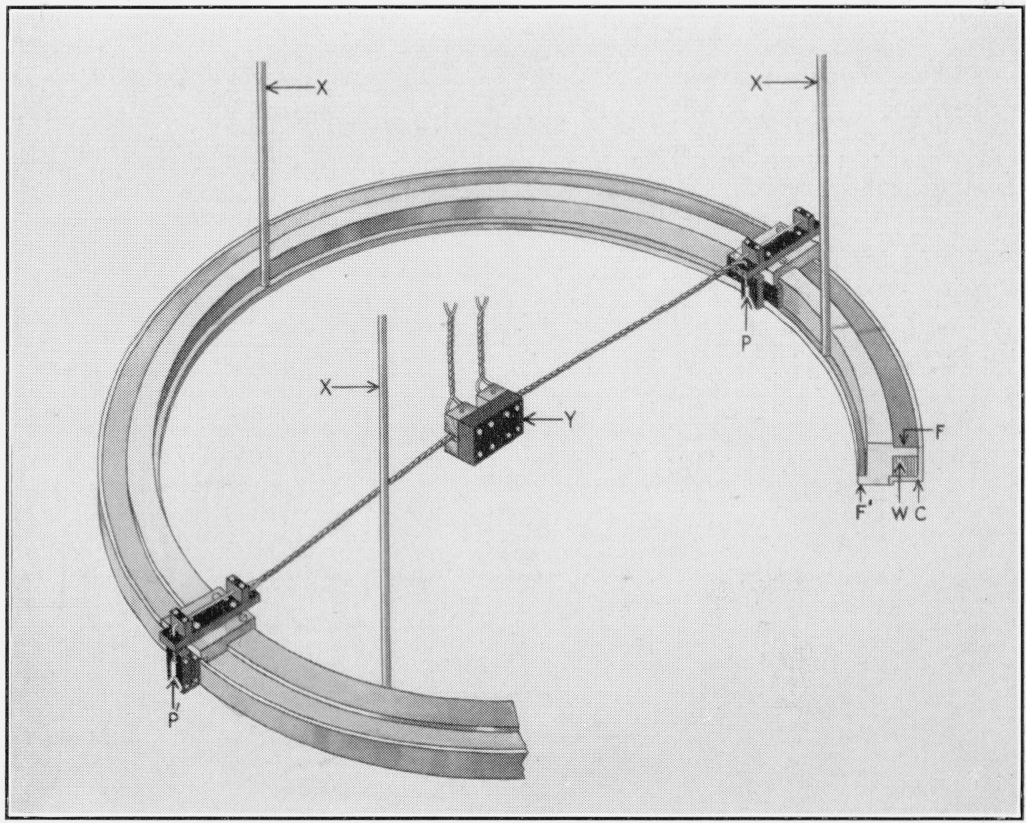

FIGURE 4.-Schematic drawing of the moving coil of aluminum ribbon, A1.

The coil was suspended from one pan of the balance by the rods, $X$. The cross section is shown at the right, where the winding, $W$, consisting of two separate ribbons, presses against the flange, $F$, and is protected by the cover, $C$. The internal flange is shown at $F^{\prime}$. The attachment of the aluminum ribbon at the beginning of one winding to the wire of the permanent leads is shown at $P$ and at the end of the other winding at $P^{\prime}$. Of the two pairs of twisted leads at the center of the coil, one pair, the current leads, was for conducting the current to the coil; the other pair, the potential leads, was used in measuring the temperature of the coil. The commutator, $Y$, was used when measuring the insulation resistance between windings. 


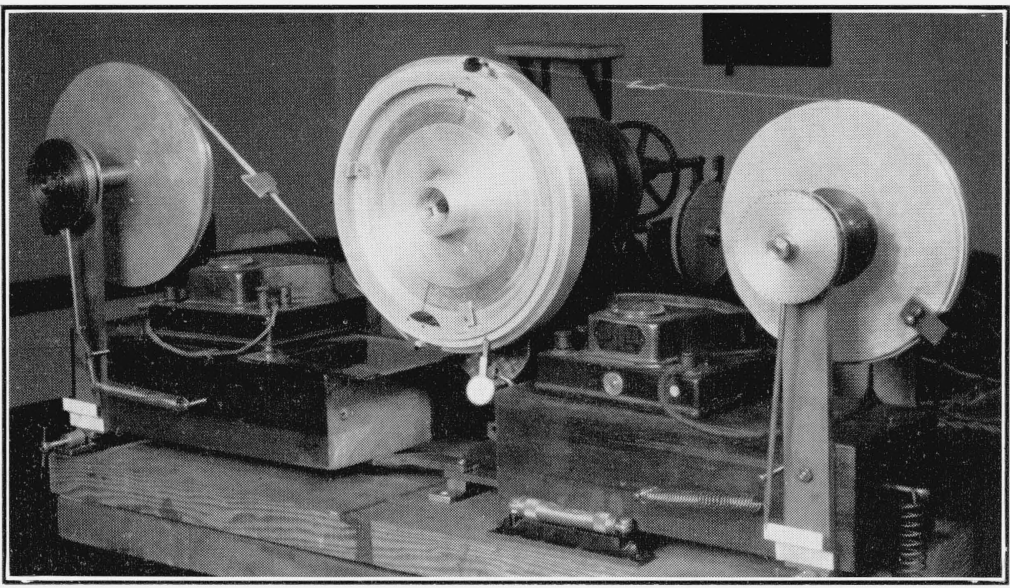

FIGURE 5.-Photograph taken at the completion of the winding of the moving coil of aluminum ribbon, coil A1.

The coil form in the center of the photograph was attached to an aluminum disk that was fastened to the spindle of a lathe which could be driven at a speed of 1 revolution in 4 minutes. The two spools which held the ribbons are at the right and left. A definite force on each ribbon was maintained by the friction clutch seen on the axle in the foreground of each spool. The force could be regulated by a nut on the axis of the clutch, and its value determined from the reading on a scale of the position of the pointer attached to the clutch. The electric circuits were so arranged that a short-circuit between turns or between either turn and the form produced a deflection on a voltmeter. Chamois-skin wipers are attached to each ribbon between its spool and the form and held in position manually during the winding.

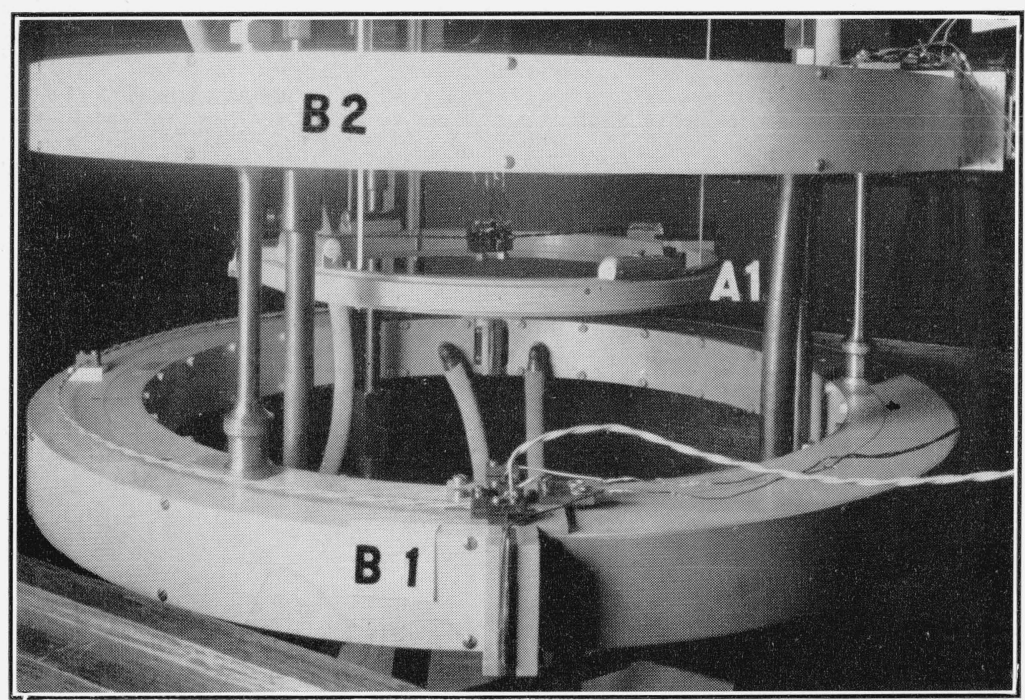

FIGURE 6.-The moving coil of aluminum ribbon, A1, mounted in the current balance between the fixed coils, $\mathrm{B} 1$ and $\mathrm{B} 2$, also of aluminum ribbon. 
the permanent leads of the fixed coils and the moving coils was minimized by placing them with their azimuths approximately $90^{\circ}$ from each other. In order to obtain the correction for all the leads, except those that are permanent, auxiliary measurements were made in which one of the wiras in the twisted pair was unsoldered from its permanent lead and connected by a drop of solder to the other wire of the twisted pair, thus making a minimum change in the position of the leads.

\section{(b) MOVING COIL OF ALUMINUM RIBBON}

The moving coil of aluminum ribbon, designated as A1, was made by winding two anodized aluminum ribbons in a compact spiral on an aluminum form. A diagram showing the cross section of the form and winding and also the method of attaching the terminals is given in figure 4. The important constants of the coil are given in table 2. The form was made from a thick sheet of aluminum alloy and was anodized before the ribbon was wound on it. The anodizing produced a layer of aluminum oxide which served to insulate the turns from each other and from the form. A layer of condenser paper was placed on the face of the form before the winding was started to improve the insulation.

The form was designed to be light and was made rigid with respect to the radial compressive forces produced by the winding by means of an internal and an external flange (see fig. 4). The external flange also served as a guide in winding the ribbon.

TABLE 2.-Constants of the moving coil of aluminum ribbon, $\mathrm{A} 1$, at $22^{\circ} \mathrm{C}$

\begin{tabular}{|c|c|c|c|}
\hline Quantity & Measured value & Quantity & Measured value \\
\hline 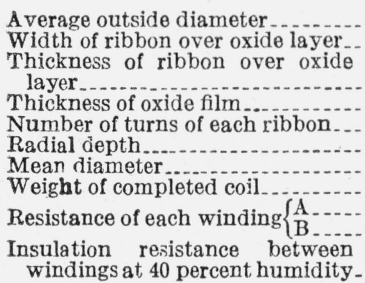 & $\begin{array}{c}25.8043 \mathrm{~cm} . \\
0.6372 \mathrm{~cm} . \\
.0072 \mathrm{~cm} . \\
.0004 \mathrm{~cm} . \\
45 . \\
0.6521 \mathrm{~cm} . \\
25.1522 \mathrm{~cm} . \\
473 \mathrm{~g} . \\
2.91 \mathrm{ohms} . \\
2.83 \text { ohms. } \\
18 \text { megohms. }\end{array}$ & $\begin{array}{l}\text { Insulation resistance between } \\
\text { frame and winding A. } \\
\text { Ellipticity-difference between } \\
\text { maximum and minimum out- } \\
\text { side diameters. } \\
\text { Compression of form during } \\
\text { winding - } \\
\text { Temperature coefficient of expan- } \\
\text { sion of the outside diameter of } \\
\text { the rompleted coill }\end{array}$ & $\begin{array}{l}0 \mathrm{ohm} . \\
0.0039 \mathrm{~cm} . \\
.0005 \mathrm{~cm} . \\
21 \times 10^{-8 / 0} \mathrm{C} \text {. }\end{array}$ \\
\hline
\end{tabular}

Each ribbon was anodized by slowly passing it through a solution of chromic acid (3 to 10 percent maintained at $40^{\circ} \mathrm{C}$ ) while it was connected to the positive terminal of a source of electric power which maintained a constant potential difference of 40 volts between the ribbon and the long iron tank containing the acid. An arrangement of reduction gearing and pulleys was devised so that the ribbon was pulled through the anodizing bath, washed, dried, and spooled in one continuous process. Each part of the strip was in the anodizing bath about an hour. About 24 hours was required to anodize one ribbon.

The two ribbons were simultaneously wound on the form, one ribbon starting from one end of a diameter, the other ribbon from the opposite end of the same diameter. A photograph taken at the completion of the winding of this coil is reproduced in figure 5. An im- 
portant feature of the set-up was the two chamois-skin wipers which cleaned the ribbon just before it reached the coil. Other features are described in the legend to the figure.

In order to make a secure mechanical fastening and to attach the electrical terminals, the ends of each ribbon were extended a short distance in a radial direction. At the inside end each ribbon passed through a slot in the form. Each slot was lined with sheets of hard rubber to insure good insulation between the ribbon and form at this point. At the outside end each ribbon was held by a clamp attached to the external flange of the form. The electrical terminals were close to the mechanical fastenings. The arrangement of fastenings and terminals is shown in figure 4 .

Electrical contact with the ribbon was made by clamping it between two sheets of platinum. The aluminum oxide, which is very hard, was removed by a "diamond file" which was made by charging a strip of copper with diamond dust. To insure good contact, filings of a hard platinum-iridium alloy were sprinkled between the aluminum ribbon and the platinum sheets. The contact resistance between the ribbon and the platinum was less than $0.004 \mathrm{ohm}$, when the coil was constructed. A wire was soldered to the platinum sheets at each end of each winding. These wires were held in a definite position by a hard-rubber frame attached to the coil form. The free ends of the two wires attached to the winding were brought close together at a point near the inside edge of the form. At this point the twisted leads were attached. The portion of the leads between these twisted leads and the winding proper was called the permanent leads of the winding. When this coil was mounted in the balance, the twisted leads attached to each winding were brought to a terminal block at the center of the coil where the windings were connected, either in series or in parallel, to the twisted pair leading to the pan of the balance. This arrangement of leads can be seen in figure 6 , which is a photograph of coil A1 mounted in the current balance between the new fixed coils, B1 and B2. An equivalent arrangement was used in measuring the ratio of the radii. When making the auxiliary measurements for determining the lead correction, one wire of a twisted pair was unsoldered from its permanent lead and then soldered to the other wire of the twisted pair with as little change in position as possible.

\section{(c) FIXED COILS OF ALUMINUM RIBBON}

The fixed coils of aluminum ribbon, designated as B1 and B2, were similar to the moving coil of that material. They were made of wider and thicker ribbon and the number of turns was larger. Also, they were arranged for water cooling. Figure 6 shows these coils in the current balance. A diagram showing the cross section of the form and winding and indicating the method of attaching terminals is given in figure 7. The important constants of the coils are given in table 3.

Each form consisted of a base ring, two flanges, and covers for the coil and water channel. These parts were made from a thick sheet of aluminum alloy. On the inside surface of the base ring a channel was 


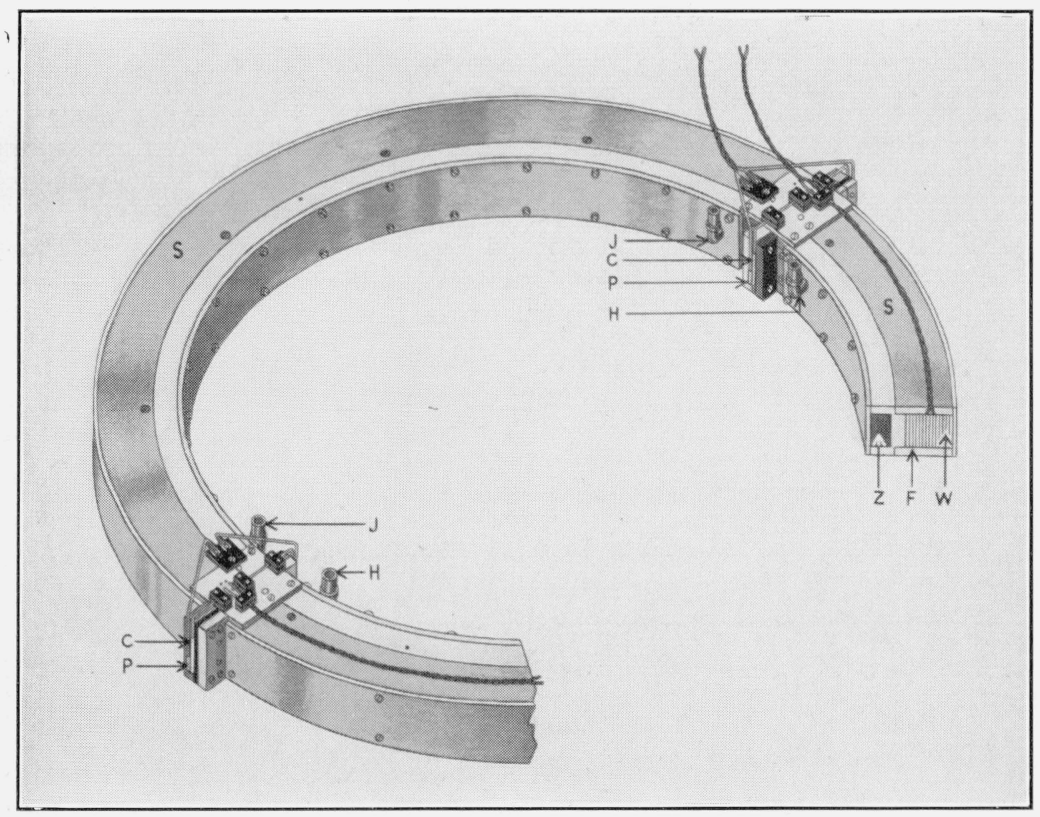

FIGURE 7.-Schematic drawing of a fixed coil of aluminum ribbon.

A fixed coil of aluminum ribbon, equivalent to either B1 or B2, is shown with its cover attached. The cross section is shown at the right. The winding, $W$, consisting of two interleaved and insulated ribbons, presses against the circular flange, $F$, which was attached before starting the winding. The two semieircular flanges, $S$, were attached after the winding was completed. The water channel, $Z$, had connections at $H-H$, and the connections to the water channel for the opposite side of the coil were at $J-J$. The connections of the aluminum ribbon to the potential leads are shown at $P-P$. The connections to the current leads are at $C-C$. The permanent current leads in the foreground are shown as connected to a twisted pair of wires which extend along the upper flange to the opposite side of the coil where they are shown as connected in parallel with the second winding and joined to a twisted pair that forms part of the external circuit. The potential drop for determining the temperature was normally measured over only one of the windings. 


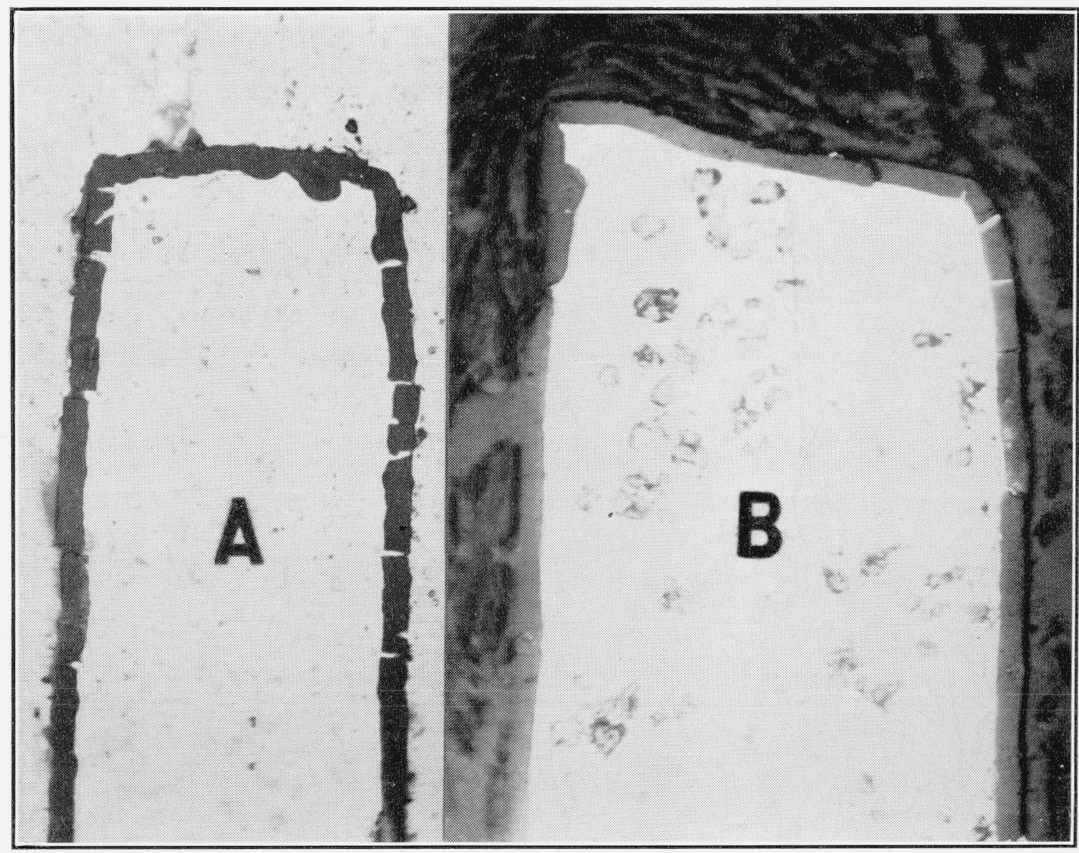

FIGURE 8.-Photomicrographs of the aluminum-oxide coating on the aluminum ribbon after it was anodized.

The ribbons were imbedded in a matrix so that a cross section could be cut and polished. Sample $A$, from coil A1, was imbedded in metal matrix; sample $B$, from coil B1, was imbedded in a Bakelite matrix. Both samples were subjected to heavy pressure in applying the matrix which probably accounts for the breaks in the oxide coating. Magnification $\times 500$ 
TABLE 3.-Constants of the fixed coils of aluminum ribbon, $\mathrm{B} 1$ and $\mathrm{B} 2$, at $22^{\circ} \mathrm{C}$

\begin{tabular}{|c|c|c|}
\hline \multirow{2}{*}{ Quantity } & \multicolumn{2}{|c|}{ Measured values } \\
\hline & $\mathrm{B} 1$ & B2 \\
\hline Average diameter of form......... & $42.7050 \mathrm{~cm}$ & 42. $7064 \mathrm{~cm}$ \\
\hline Width of ribbon over oxide layer & $2.5410 \mathrm{~cm}$ & $2.5409 \mathrm{~cm}$ \\
\hline Thickness of ribbon over oxide layer..... & $0.0104 \mathrm{~cm}$ & $0.0104 \mathrm{~cm}$ \\
\hline Thickness of oxide film.................. & $.0006 \mathrm{~cm}$ & $.0006 \mathrm{~cm}$ \\
\hline Number of turns of each ribbon. & $125^{\circ}$ & $125^{\circ}$ \\
\hline 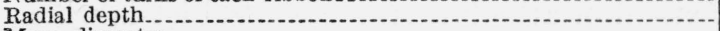 & $2.624 \mathrm{~cm}$ & $2.637 \mathrm{~cm}$ \\
\hline 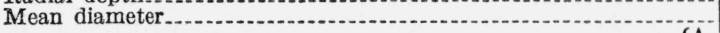 & $45.329 \mathrm{~cm}$ & $45.344 \mathrm{~cm}$ \\
\hline Resistance of each winding......... $\left\{\begin{array}{l}A \\
B\end{array}\right.$ & $2.176 \mathrm{ohms}$ & $\begin{array}{l}2.150 \mathrm{ohms} \\
2.182 \mathrm{ohms}\end{array}$ \\
\hline Insulation resistance between windings at 40 percent humidity & 0.1 megohm & s 0.1 megohm \\
\hline Insulation resistance between frame and windings & 2500 megohms & 5000 megohms \\
\hline $\begin{array}{l}\text { Ellipticity of form-difference between maximum and minimum } \\
\text { diameters. }\end{array}$ & $0.0052 \mathrm{~cm}$ & $0.0032 \mathrm{~cm}$ \\
\hline $\begin{array}{l}\text { Temperature coefficient of expansion of the outside diameter of the } \\
\text { completed coil }\end{array}$ & $21.1 \times 10^{-8} /{ }^{\circ} \mathrm{C}$ & $20.7 \times 10^{-6 /{ }^{\circ} \mathrm{O}}$ \\
\hline
\end{tabular}

- A short-circuit between windings occurred just as measurements were completed. (See footnote 8.)

cut, except for $10^{\circ}$ at each end of a diameter. The portions in which the channel was not cut were utilized for bringing out the inside leads of the two ribbons. The two portions of the channel were fitted with watertight covers, and each had a water connection at each end. The outside cover of the coil was merely to protect it against accident. The forms were anodized before the coils were wound, and the oxide coating gave sufficient insulation, so that no paper was used, as was the case with the moving coil.

The ribbons were anodized by the same process that was used for anodizing the ribbons for the moving coil. The same tank was used, but the ribbon was so long that about 6 days of continuous operation were needed for anodizing a single ribbon. This required a few modifications in the procedure. It was necessary to add chromic acid from time to time to maintain its concentration. A spray of tap water was used to wash the ribbon after it left the anodizing bath and before it was washed with distilled water.

In order to determine the thickness of the oxide coating, samples of ribbon were mounted in a matrix, and a cross section was cut and polished. Photomicrographs were made showing the thickness of the oxide layer, which could be readily measured. Two of these photomicrographs are reproduced in figure 8 , one from the moving coil, $\mathrm{A} 1$, and one from fixed coil, B1. They show that the coating is quite uniform, even at the corners.

The first coils that were wound were not satisfactory. The ribbon was longer at the edges than in the center, apparently as a result of being cut by dull shears. As a result, there was a slight ruffing at each edge, which was barely noticeable when a short length of the ribbon was held straight. When wound in a coil, the ribbon did not lie flat but was curved with its concave side away from the center of the coil. When about 250 turns had been wound, this concavity amounted to more than $1 \mathrm{~mm}$. This winding was removed and the forms were rewound with new ribbon. The thickness of the new ribbon was twice that of the first ribbon $(0.1 \mathrm{~mm}$ vs. $0.05 \mathrm{~mm})$, and 
the new ribbon was hard-rolled aluminum, whereas the first was soft or annealed aluminum. The new ribbon, which was cut in a different factory, did not show any ruffles, but the edges had been slightly turned by the shearing. The ribbon, before anodizing, was passed between rollers which flattened the edges, but did not otherwise change its form. The second winding produced coils which were satisfactory:

The terminals were attached to these coils in nearly the same manner as those of the moving coil of aluminum ribbon. A slight modification was made in the method of attaching the potential leads which were used in measuring the resistance of the coil. In the moving coil of aluminum ribbon, the potential leads were attached to the current leads at the point where the two windings were connected in parallel, so that the measured resistance included the contact resistances between the platinum sheets and the aluminum ribbon. In the fixed coils, separate platinum sheets were provided for the potential terminals. There was no difference in accuracy between the two methods.

\section{MEASUREMENT OF THE DIMENSIONS OF THE COILS}

The new coils were so constructed that their mechanical dimensions could be measured with greater accuracy than could those of the older coils. The dimensions were required in order to compute the corrections for the cross sections of the coils.

\section{DIAMETERS OF THE COILS}

The diameters of the coils were measured by a motor-operated micrometer ${ }^{B}$ mounted in a frame, or ring, of invar. The micrometer head was graduated to read directly in microns. The divisions were about a millimeter apart, so that readings could be made with an accuracy of 0.1 or $0.2 \mu$. The micrometer would, under favorable conditions, repeat readings as accurately as it could be read.

The micrometer was used merely to obtain the difference between the diameter of a coil and the length of an end standard. The end standard never differed in length by more than a few tenths of a millimeter from the diameter to be measured. For this difference in length, the calibration error of the micrometer did not introduce an error as great as $0.1 \mu$. The end standard either consisted of a number of calibrated gage blocks which had been wrung together or was a rod with spherical ends which had been compared by the micrometer with such gage blocks. The largest source of error was the uncertainty in the uniformity of the temperature throughout the measuring chamber.

The outside diameter of the solenoidal moving coil, P1, was measured in 10 axial planes and at 3 altitudes in each plane.

The diameter of the form of the moving coil of aluminum ribbon was measured before winding, and the diameter over the outside turn of ribbon was measured after winding. The method was the same as for the solenoidal coil, except that only one altitude was used in determining the mean diameter. These measurements were used in determining the radial depth of the coil and will be discussed under that heading. A ledge below the winding space was measured before

\footnotetext{
- Moon, BS J. of Research 10, 249 (1933) RP528.
} 
and after winding, in order to obtain an estimate of the compression caused by the winding.

\section{AXIAL WIDTHS OF THE WINDINGS}

The axial width of the solenoidal coil was equal to the pitch times the number of turns. The pitch was determined by measuring, with a traveling microscope, the distance between the centers of wires on the two outside turns and dividing this distance by one less than the total number of turns. In order to be able to set the microscope on the center of the wire, lines were ruled on the elliptical spots that had been polished on the wires for determining the uniformity of diameter of the coil. Two lines were ruled ${ }^{7}$ on each spot, using opposite sides of the wire as a guide for the ruling device. The intersection of the cross hairs in the traveling microscope was set midway between the two lines on one outside wire and the reading of the micrometer recorded. The microscope was then moved by the micrometer screw until it was set on the corresponding position on the other outside wire. The difference between readings, when corrected for the calibration errors of the micrometer screw, gave the distance between the outside turns. The calibration was made by making readings with the traveling microscope on two graduations of a standard scale. Also, readings were made on the middle wire to determine the uniformity of pitch. The values obtained are given in table 4.

TABLE 4.-Axial width of solenoidal coil in four azimuths at $24^{\circ} \mathrm{C}$

\begin{tabular}{|c|c|c|c|c|}
\hline \multirow[b]{2}{*}{ Arimuth } & \multicolumn{4}{|c|}{ Difference in micrometer readings } \\
\hline & $\begin{array}{l}\text { Wires } \\
1 \text { to } 21\end{array}$ & $\begin{array}{l}\text { Wires } \\
21 \text { to } 41\end{array}$ & $\begin{array}{l}\text { Wires } \\
1 \text { to } 41\end{array}$ & $\begin{array}{l}\text { Lines } 1 \text { to } \\
27 \text { on } \\
\text { standard } \\
\text { scale }\end{array}$ \\
\hline $\begin{array}{c}\text { Degrees } \\
0 \\
90 \\
180 \\
270\end{array}$ & $\begin{array}{c}m m \\
12.998 \\
13.000 \\
13.002 \\
13.001\end{array}$ & $\begin{array}{c}m m \\
13.001 \\
13.000 \\
12.999 \\
12.999\end{array}$ & $\begin{array}{c}m m \\
25.999 \\
26.000 \\
26.001 \\
26.000\end{array}$ & $\begin{array}{c}\mathrm{mm} \\
26.001 \\
26.001 \\
26.001\end{array}$ \\
\hline Average.... & 13. 000 & 13.000 & 26.000 & 26.001 \\
\hline
\end{tabular}

Note.-The length between lines 1 and 27 of the standard scale as furnished by the Interferometry Section of this Bureau was $26.001 \mathrm{~mm}$ at $24^{\circ} \mathrm{C}$. As this length agrees exactly with the reading of the micrometer microscope, there was no calibration correction.

The pitch was $0.65000 \mathrm{~mm}$ and the axial width was $26.650 \mathrm{~mm}$.

The diameter of the wire on the solenoidal moving coil was measured with a special micrometer caliper which could be read to tenths of a micron. The variation in diameter with different azimuths was less than $1 \mu$. The average diameter of two samples, one from the beginning and one from the end of the winding, was $0.5123 \mathrm{~mm}$ for each sample.

The axial widths of the winding of the ribbon coils were determined from the width of the ribbon, since the effect of the axial displacement of the ribbons relative to the mean position is negligible as shown later. The width of the ribbon was measured by comparing it with a gage block by means of a hand micrometer. To prevent the ribbon from deforming, it was held in a clamp, the parallel faces of which had

7 A photomicrograph showing spots with lines ruled on them is given in figure 4, p. 380, of the paper by Curtis, Moon, and Sparks. The method of ruling the lines is also described in that paper. (See reference in footnote 4.) 
such dimensions that the ribbon extended a few tenths of a millimeter on each side of them. The micrometer reading could be estimated to $1 \mu$. A series of values obtained from samples of the ribbon used on each of the ribbon coils is given in table 5 . These results indicate that the average width of the ribbon on any coil is not in error by as much as $10 \mu$.

The average axial displacement of the turns from the mean position was estimated from measurements at a few places where the displacement appeared to be largest. Since the winding was guided by a flange, there was no cumulative error. However, in winding, the operators could not keep the ribbon against the flange at every instant and even when this was accomplished, a turn sometimes slipped away from the flange as a result of the pressure of outside turns. To measure the displacement of one turn relative to an adjacent one, a microscope with an objective having a focal length of $5 \mathrm{~mm}$ was placed with its axis perpendicular to the plane of the coil, so that the edges of the two strips were both in the field of the microscope. The microscope was focused first on one, then on the other of the edges, and the motion of the microscope tube was measured.

TABLE 5.-Width of the aluminum ribbon on the different coils

[Measurements made on the anodized ribbon]

\begin{tabular}{|c|c|c|c|c|c|c|c|c|c|c|}
\hline \multirow[b]{2}{*}{$\begin{array}{l}\text { Wind- } \\
\text { ing }\end{array}$} & \multirow[b]{2}{*}{ Position } & \multicolumn{3}{|c|}{ Coil A1 } & \multicolumn{3}{|c|}{ Coil B1 } & \multicolumn{3}{|c|}{ Coil $B 2$} \\
\hline & & $\begin{array}{l}\text { Num- } \\
\text { ber of } \\
\text { ob- } \\
\text { served } \\
\text { posi- } \\
\text { tions }\end{array}$ & Width & $\begin{array}{l}\text { Aver- } \\
\text { age de- } \\
\text { viation } \\
\text { from } \\
\text { mean } \\
\text { of } \\
\text { group }\end{array}$ & $\begin{array}{l}\text { Num- } \\
\text { ber of } \\
\text { ob- } \\
\text { served } \\
\text { posi- } \\
\text { tions }\end{array}$ & Width & $\begin{array}{l}\text { A ver- } \\
\text { age de- } \\
\text { viation } \\
\text { from } \\
\text { mean } \\
\text { of } \\
\text { group }\end{array}$ & $\begin{array}{l}\text { Num- } \\
\text { ber of } \\
\text { ob- } \\
\text { served } \\
\text { posi- } \\
\text { tions }\end{array}$ & Width & $\begin{array}{l}\text { A ver- } \\
\text { age de- } \\
\text { viation } \\
\text { from } \\
\text { mean } \\
\text { of } \\
\text { group }\end{array}$ \\
\hline B. & $\left\{\begin{array}{l}\text { Beginning... } \\
\text { End...... } \\
\text { Beginning. } \\
\text { End. }\end{array}\right.$ & $\left\{\begin{array}{r}34 \\
34 \\
34 \\
34\end{array}\right.$ & $\begin{array}{l}m m \\
6.374 \\
6.370 \\
6.365 \\
6.379\end{array}$ & $\begin{array}{l}\mu \\
\pm 8 \\
10\end{array}$ & $\begin{array}{l}52 \\
27 \\
40 \\
23\end{array}$ & $\begin{array}{c}m m \\
25.398 \\
25.417 \\
25.408 \\
25.416\end{array}$ & $\begin{array}{r}\mu \\
\pm 5 \\
7 \\
7 \\
8\end{array}$ & $\begin{array}{l}53 \\
23 \\
38 \\
18\end{array}$ & $\begin{array}{c}\text { mm } \\
25.436 \\
25.401 \\
25.394 \\
25.404\end{array}$ & $\begin{array}{r}\mu \\
\pm 9 \\
7 \\
8 \\
10\end{array}$ \\
\hline \multicolumn{3}{|c|}{$\begin{array}{l}\text { Average } \\
\text { Twice thickness of oxide film }\end{array}$} & $\begin{array}{l}6.372 \\
0.008\end{array}$ & & & $\begin{array}{r}25.410 \\
0.012\end{array}$ & & (-n-1 & $\begin{array}{r}25.409 \\
0.012\end{array}$ & (n) \\
\hline \multicolumn{3}{|c|}{$\begin{array}{l}\text { Width of aluminum } \\
\text { A verage deviation of the mean of } \\
\text { each group from the average of } \\
\text { all the groups.... }\end{array}$} & $\begin{array}{r}6.364 \\
\pm 0.004\end{array}$ & & & $\begin{array}{r}25.398 \\
\pm 0.007\end{array}$ & & & $\begin{array}{r}25.397 \\
\pm 0.014\end{array}$ & \\
\hline
\end{tabular}

Readings could be repeated to $0.01 \mathrm{~mm}$. Measurements made at four positions on coil B1, where the displacement seemed to be the largest, gave differences between adjacent turns of $0.46,0.43,0.30$, and 0.28 $\mathrm{mm}$. It was estimated that the average value was less than $0.1 \mathrm{~mm}$. A computation by the formula given in appendix II showed that the effect of such a displacement on the absolute value of the current was less than 1 part in a million. Hence, an extensive survey was not undertaken.

\section{RADIAL DEPTHS OF THE WINDINGS}

Since the solenoidal coil had only a single layer, no measurements of the radial depth, other than the diameter of the wire, were made. 
The radial depth of moving coil A1 was obtained from measurements, with a micrometer, of the diameter of the form before winding and of the diameter over the winding after completion of the coil. Corrections were introduced for the compression of the form and for a layer of paper, $15 \mu$ thick, which was placed over the form before the winding was started. The compression was determined by measuring the ledge outside the winding both before and after winding. These measurements showed that the diameter which extended from one terminal to the other was not compressed, while a diameter at right angles to this one was compressed $12 \mu$. The average compression was $5 \mu$.

The diameter over the winding was measured with a micrometer having flat measuring faces that extended the full width of the ribbon. Since the ribbon was slightly concave outwards, the micrometer faces made contact with the two outside edges of the ribbon, but the measuring force of $300 \mathrm{~g}$ compressed these edges by a measurable amount. The assumption was made that the reading obtained with this pressure gave the average outside diameter, by means of which the average radial depth was determined. Since the maximum difference between the radial depth at the edge of the ribbons and that at their centers was only $100 \mu$, as determined by comparison with a template having a known radius of curvature, a measurement at either place with zero pressure would give a result that differed from the average value by about $50 \mu$. With the pressure used it seems improbable that there was an error of more than $20 \mu$ in the radial depth. (See table 12.)

The diameter was measured at 10 positions before winding and at the same 10 positions after winding. However, because of the compression and change in shape resulting from the winding, the difference between the readings at any one place made before and after winding does not give twice the radial depth at that place. The average radial depth was obtained from the average diameter before winding, the average diameter after winding, the average compression of the form, and the thickness of the paper layer over the form. The radial depth obtained by this method was, by two independent sets of data,

and

$$
\begin{aligned}
& 0.6520 \mathrm{~cm} \text { at } 20^{\circ} \mathrm{C} \\
& 0.6523 \mathrm{~cm} \text { at } 30^{\circ} \mathrm{C} \text {. }
\end{aligned}
$$

The difference of $3 \mu$ between the values at the two temperatures is about twice that which would arise from the thermal expansion of the aluminum. The value used in the computations was

\section{$0.6521 \mathrm{~cm}$ at $22^{\circ} \mathrm{C}$.}

As already explained, this may be in error by as much as $20 \mu$ because of an uncertainty in the amount of compression produced by the measuring force. The readings of the micrometer at any point could always be reproduced within 1 or $2 \mu$, generally within a few tenths of a micron.

The radial depths of fixed coils B1 and B2 were measured by a traveling microscope. In this arrangement settings were made on the first few turns at the inside edge of the coil, a few in the middle of the coil, 
and a few at the outside edge. This was done for six different equally spaced radial positions. The setting of the micrometer screw moving the microscope could be estimated to $1 \mu$.

TABLE 6.-Radial depth of the fixed coils of aluminum ribbon

[Measurements were made on the exposed edge of the winding before attaching the semicircular flanges]

\begin{tabular}{|c|c|c|}
\hline Azimuth & B1 & $\mathrm{B} 2$ \\
\hline $\begin{array}{l}\text { Degrees } \\
0 \\
00 \\
120 \\
240 \\
300\end{array}$ & $\begin{array}{r}c m \\
2.6266 \\
302 \\
208 \\
246 \\
265 \\
213\end{array}$ & $\begin{array}{r}c m \\
2.6479 \\
450 \\
378 \\
420 \\
395 \\
385\end{array}$ \\
\hline $\begin{array}{l}\text { Average radial depth at edge..... } \\
\text { Concavity correction } \\
\text { Mean radial depth } \\
\text { Average deviation from mean.... }\end{array}$ & $\begin{array}{r}2.6250 \\
-0.0013 \\
2.6237 \\
\pm 0.0028\end{array}$ & $\begin{array}{r}2.6418 \\
-0.0045 \\
2.6373 \\
\pm 0.0032\end{array}$ \\
\hline
\end{tabular}

The values of the radial depth given for the different azimuths in table 6 are for an edge of the coil. Since the ribbon was, throughout the winding, slightly concave outwards with the largest concavity at the outside turn, the mean value of the radial depth was less than that obtained by measurements on the edge of the coil. In order to obtain the necessary correction to the measured depth, a large number of observations were made on the concavity of the outside turn. While in some azimuths the depth of the concavity was as much as $0.02 \mathrm{~cm}$, yet the average depth gave a correction for concavity of only 0.0013 $\mathrm{cm}$ for $\mathrm{B} 1$ and $0.0045 \mathrm{~cm}$ for $\mathrm{B} 2$.

\section{ELECTRIC CIRCUIT OF THE CURRENT BALANCE}

The same electric circuit used in the previous work was employed for a part of the present work. In this circuit the fixed and moving coils were connected in series. A modification in which the moving coil was connected in parallel with the two fixed coils was, however, used for some of the observations. A diagram of the electric circuit with the coils in series is given in figure 5 of the previous publication. A diagram of the electric circuit with the coils in parallel is given in figure 9 of this paper. All of the conditions which are necessary for an accurate measurement of the current, as enumerated in the previous paper, are as well fulfilled by the parallel connection as by the series connection.

\section{ADJUSTMENT OF THE CURRENT}

In the series connection of the coils, any variation in the current from the selected value was indicated by the deflection of a galvanometer, and this value was maintained by the adjustment of a single resistor. In the parallel connection, two different currents had to be maintained constant. When the series connection was used, a single observer maintained the current and read the deflections of the bal- 
ance. When the parallel connection was used, two observers were generally employed, one to maintain the two currents and the other to read the balance. In either case, the variations in the currents were less than 1 part in a million of their nominal values.

\section{THE STORAGE BATTERY}

The current was supplied by a lead storage battery. In order that the current might be maintained sufficiently constant by adjusting the resistance once or twice a minute, a battery of large capacity was required. For the series connection where the maximum current was 1 ampere, a 100-volt, 400-ampere-hour battery was satisfactory. For

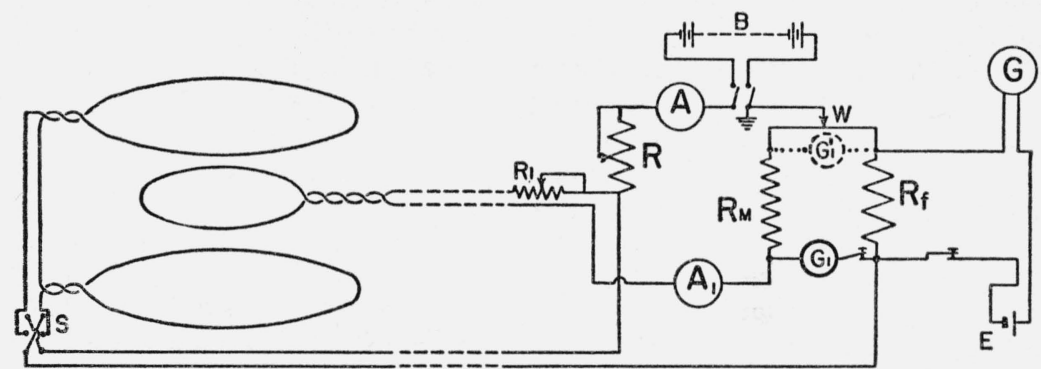

FIGURE 9.-Electric circuit of the current balance with coils in parallel.

The total current and the current through the moving coil were adjusted by the resistances, $R$ and $R_{1}$, to their desired values. The approximate values were determined from the readings of the ammeters $A$ and $A_{1}$; the precise values by determining the drop in potential over the resistances, $R_{m}$ and $R_{f}$. For the precise adjustment, the deflection of the galvanometer, $G_{1}{ }^{\prime}$, was made zero by adjusting the slide wire $W$, which consisted of a clamp on a heavy copper wire. Then $R_{1}$ was adjusted until there was no deflection of $G_{1}$. Finally, $R$ was adjusted until there was no deflection of the galvanometer, $G$, which was in the circuit with the standard cell, $E$. During the operation of the balance, $W$, was adjusted only occasionally, but $R$ and $R_{1}$ were adjusted almost continuously to keep the deflections of $Q$ and $G_{1}$ at zero.

the parallel connection, the maximum current used was 6 amperes, and a 20-volt, 2,000-ampere-hour battery was employed.

\section{REVERSAL OF THE CURRENT IN THE FIXED COILS OF ALUMINUM RIBBON}

The reversal of the current in the fixed coils of aluminum ribbon was given some study because of the large capacitance between the two windings. When the two windings were connected in series, there was a storage of electricity on the surfaces of the ribbons because of the potential difference between adjacent surfaces. Oscillograms showed that the rise in potential across the coil, when the circuit was opened, was less when the windings were in series than when they were in parallel. Also, it was shown that the rise in voltage was much greater when opening the circuit with 0.7 ampere in the coils than when decreasing the current from 4 to 2.5 amperes. Hence, the step-bystep reversing switch which was used ( $S$ in figure 9 ) was so designed that the first step made a large change in current and the last step a relatively small change.

\section{INSULATION RESISTANCE}

The insulation resistance between the frame and each winding of the fixed coils of aluminum strips B1 and B2 was more than $10^{9} \mathrm{ohms}$. 
As the potential difference between the windings and frame during an observation was never more than 10 volts, the leakage current to the grounded frame was always negligible. The insulation resistance between the two windings was, for each fixed coil, ${ }^{8}$ about $10^{5} \mathrm{ohms}$, when measured after a potential of 1.5 volts had been applied for 1 minute. When the windings were connected in parallel, the potential difference between windings was never more than 0.04 volt, so that the leakage current between them was less than $10^{-6}$ ampere and hence negligible. However, when the windings were connected in series, the potential difference between turns, though never more than 2.5 volts, produced a leakage current which was not quite negligible, and a small correction was required. In this case the insulation resistance had to be measured with the same time interval after applying the potential as elapsed in making the other observations. An example to show that this correction can be made with precision is given in table 7 , which lists data taken in connection with a measurement of the ratio of the radii. The uncertainty in the absolute value of a current, caused by the leakage current between the windings of the fixed coils when connected in series, was less than 2 parts in a million.

TABLE 7.-Example to show the precision that can be attained by applying the correction for the insulation resistance when the windings of a fixed coil are connected in series

[Different elapsed times after reversal of the current were used in measuring the ratio of the radii, and the same time intervals were used between reversals of the potential when measuring the insulation resistance. Each result given, both for the ratio of the radii and for the insulation resistance, is the average of four observation :.]

\begin{tabular}{|c|c|c|c|c|}
\hline \multirow{2}{*}{ Time between reversals } & \multicolumn{2}{|c|}{$\begin{array}{c}\text { Results-mean of four } \\
\text { sets }\end{array}$} & \multirow{2}{*}{$\begin{array}{l}\text { Correction } \\
\text { computed } \\
\text { from } \\
\text { insulation } \\
\text { resistance }\end{array}$} & \multirow{2}{*}{$\begin{array}{l}\text { Corrected } \\
\text { ratio of } \\
\text { radii, } \\
\text { A1: Bi }\end{array}$} \\
\hline & $\begin{array}{l}\text { Apparent } \\
\text { ratio of } \\
\text { radii }\end{array}$ & $\begin{array}{l}\text { Apparent } \\
\text { insulation } \\
\text { resistance }\end{array}$ & & \\
\hline $\begin{array}{c}\text { Minutes } \\
1 \text { 1 }\end{array}$ & $\begin{array}{r}0.5545311 \\
21 \\
38\end{array}$ & $\begin{array}{r}\text { Megohms } \\
0.10 \\
.13 \\
.16\end{array}$ & $\begin{array}{r}\text { ppm } \\
10 \\
8 \\
6\end{array}$ & $\begin{array}{r}0.5545366 \\
65 \\
71\end{array}$ \\
\hline Mean...... & & & & 0.5545367 \\
\hline
\end{tabular}

In the moving coil of aluminum strip, one winding was accidentally and permanently connected to the frame during manufacture. This grounding caused no leakage to earth, since in the balance the frame and pan of the balance were insulated from earth by the agate planes

\footnotetext{
${ }^{3}$ Near the end of the observations a short-circuit developed between the two windings of coil B2. Before continuing observations with this coil after the short-circuit was observed, measurements were made to insure that the coil could be used with its windings in parallel in such a way that there could be no current through the short-circuit. By connecting a galvanometer to one winding and sending a current throu $\sigma \mathrm{h}$ the other winding, it was first established that there was only a single short-circuit between the windings. Since there was no deflection of the galvanometer, there could have been only one short-circuit. By connecting a battery from a terminal of one ribbon to a terminal of the other, and measuring the potential difference between the two other terminals, the resistance of the short-circuit was found to be 0.0008 ohm.

To make certain that, when the two windings were used in parallel, the potential difference between windings at the point where they were in contact was zero, a resistance equal to that of about a half a turn of ribbon was added to the inside end of one winding and the outside end of the other winding. By measuring the resistances of the different parts of the windings, the amount and location of the required resistance could be accurately determined. The results obtained with this arrangement after the short-circuit occurred differed from those obtained before the short-circuit occurred by 1 part in a million, which is within experimental error. (See footnote to table 10.)
} 
of the balance, and in measuring the ratio of the radii the frame was mounted on an insulated support. The insulation resistance between windings was 18 megohms or more, depending on the humidity of the surrounding air. Since the windings were always connected in parallel, the potential difference between windings was only a small fraction of a volt, and the leakage current was negligible.

There was no possibility of measuring insulation resistance with the solenoidal moving coil, as it was a single winding on a glass form. However, it seems certain that leakage currents were not sufficiently large to introduce an error of 1 part in a million in the final results. Static charges might have collected on the glass form, but the electrostatic forces produced by them were eliminated by the reversal of the current in the fixed coils.

\section{COMPUTATION OF THE MAXIMUM FORCE FOR UNIT CURRENT}

The computation of the maximum force per unit current in the coils of a current balance was divided into two parts: First, the force for filaments at the centers of the windings, and second, the corrections for the finite cross sections of the coils.

\section{MAXIMUM FORCE BETWEEN CIRCULAR FILAMENTS}

The maximum force between circular filaments was computed by Maxwell's elliptic-integral formula which was given in the previous paper. The variation formulas there given were also applicable to the present work. However, a more accurate empirical formula has. been devised for determining the axial distance at which the force per unit current between two filaments in the form of coaxial circles is a maximum. This formula is

$$
y_{m}=0.5-0.45 \alpha^{2}-0.0633 \alpha^{4} \quad \text { if } 0<\alpha<0.65,
$$

where

$y_{m}=$ ratio of the axial distance for maximum force to the radius of the larger filament, $\alpha=$ ratio of the radii of the filaments.

This formula differs from the one given in the previous publication only in the coefficient of the last term, which was there given as 0.0625 . The range of the present formula is less than the one formerly given, but in its range the maximum numerical difference between the values of $y_{m}$ obtained by it and those given in Grover's table ${ }^{9}$ is only 50 parts per million, which is about one-tenth of the difference obtained with the previous formula. As the error in the computed force is a function of the square of the error in the value of $y_{m}$, the improved formula gives a value of $y_{m}$ which will not introduce an error of as much as 1 part in a hundred million in the computed force.

\section{MAXIMUM FORCE BETWEEN COAXIAL COILS}

The maximum force between coaxial coils differs, for two reasons, from that which would be obtained if the current in each coil were concentrated in a filament at the geometric center of its cross section.

- This is table 4, nage 372, of Grover's paper on the maximum force between two coaxial circular currents. Bul. BS 12, 317 (1915) S255.

$139015-39-2$ 
In the first place, the force between coils is different from that between filaments, because at any point the magnetic field of a coil is, in general, different in both magnitude and direction from that of a central filament with an equivalent current. The correction term to the force for this difference in magnetic fields is given in eq 4 of appendix I.

In the second place, the distance for maximum force is not the same for coils as for filaments. The correction terms to the force between the coils, when both these effects are considered, are given in eq 10 of appendix I. This equation is an extension of eq 7 of the previous paper. The additional terms were required only when moving coil P1 was being used.

Before the derivation of the equations in the appendix, a method was developed for computing the current from the measured distance between the coils when the force per unit current was a maximum. This treatment was necessary when using moving coil P1 and fixed coils $\mathrm{S} 1$ and $\mathrm{S} 2$ since in this case the axial distance for maximum force was so much greater for the coils than for the filaments at their centers that the correction for this difference as given in the previous paper was not sufficiently precise. Hence, after the distance between the fixed coils had been adjusted by trial until the force per unit current on the moving coil was the maximum that could be obtained, the distance between the fixed coils was measured by a micrometer. The distance, $z$, between the plane of either and that of the moving coil was determined from this distance and the dimensions of the coils. Then the force per unit current was computed by eq 6 of Snow's paper. ${ }^{10}$ This equation applies even if $z$ is not the distance for maximum force between filaments. However, in evaluating the $\Delta$ 's it is necessary to know $\lambda_{1}$, which is zero only when $z$ has the value required to make the force between the filaments a maximum. The formula for $\lambda_{1}$, which has not been previously given except as a derivative, is

$$
\begin{aligned}
\lambda_{1} & =1-\frac{y^{2} k^{2}}{2 \alpha\left(1-k^{2}\right)}\left[2-k^{2}+\frac{3 y k^{2}}{\sqrt{\alpha F}}\left(\frac{M}{\sqrt{a_{1} a_{2}}}\right)\right] \\
& =1-\frac{y^{2} k^{2}}{2 \alpha\left(1-k^{2}\right)}\left[2-k^{2}+3 k^{2} \phi / \psi\right]
\end{aligned}
$$

where $\alpha=a_{2} / a_{1}, y=z / a_{1}, k^{2}=4 a_{1} a_{2} /\left[\left(a_{1}+a_{2}\right)^{2}+y^{2}\right]$, and $M$ and $F$ are, respectively, the mutual inductance and the force per unit current between the filaments at the centers of the windings. ${ }^{11}$ The complete formulas for $\lambda_{2}, \lambda_{3}$, and $\lambda_{4}$, when $\lambda_{1} \neq 0$, are given in Snow's paper (see footnote 10). The computed value of the force per unit current by this method differed by less than 2 parts per million from that obtained by the complete formula, as given in appendix $\mathrm{I}$.

\section{RATIO OF THE RADII OF THE COILS}

The ratio of the radius of each moving coil to that of each fixed coil was determined by an electromagnetic method. A fixed and a moving coil were mounted with their centers coincident and their planes vertical and in the magnetic meridian. Currents were then sent through the coils in opposite directions, so that their magnetic fields had opposite directions at the common center. With a fixed current in one coil, the current in the second coil was adjusted until a reversal of both currents did not produce a steady deflection of a magnet placed at the common center of the coils. Then the magnetic fields at the center of the coils were equal and opposite, and the ratio of the radii of the coils was equal to the product of the ratio of

\footnotetext{
10 BS J. Research 11, 681 (1933) RP615.
}

11 The functions $\phi=M / \sqrt{a_{1} a_{2}}$ and $\psi=F \sqrt{a} / y=F \sqrt{a_{1} a_{2}} / z$ are tabulated with $k^{2}$ as argument by Nagaoka and Sakurai, table 2, Sci. Pap. of the Institute of Physical and Chemical Research, Tokyo, 1927. 
the number of turns of wire on the coils and the ratio of the currents in the coils. Small corrections were made for the length of the magnet, the temperature and load coefficients of the coils, the leads, and the sectional dimensions of the coils. All of these corrections were made in the manner described in the previous paper, but the formula for the correction for the sectional dimensions, which is in the form of a power series, was extended to make it sufficiently accurate for use with the solenoidal coil.

Only one variation in procedure has been introduced since the method was described in the previous publication. The effect of this variation is discussed in the following section, but for all other details of procedure in measuring the ratio of the radii the reader is referred to the previous publication. Measurements with the two windings in series were made only with the fixed coils of aluminum ribbon and in this case required a correction because of the relatively low insulation resistance between the windings. This correction has been discussed in section IV-4, and an illustrative example is given in table 7.

\section{TEMPERATURE AND LOAD COEFFICIENTS OF THE COILS}

The temperature and load coefficients of expansion of the coils are given in table 8 . The temperature coefficient of each of the fixed coils was determined in connection with measurements of the ratio of its radius to that of one of the moving coils. The data for a given coil were obtained by keeping the temperature of the room constant and changing the temperature of the water circulating through the fixed coil. In this way the temperature of the moving coil remained approximately constant, so the change in ratio resulted principally from the change in temperature of the fixed coil. From these data, the temperature coefficient of the fixed coil was computed.

TABLE 8.-Temperature and load coefficients of expansion of the coils

\begin{tabular}{|c|c|c|c|c|c|}
\hline \multirow{2}{*}{$\begin{array}{l}\text { Designation } \\
\text { of coil }\end{array}$} & \multirow{2}{*}{ Kind of coil } & \multirow{2}{*}{ Material of winding } & \multirow{2}{*}{ Material of form } & \multicolumn{2}{|c|}{$\begin{array}{l}\text { Coefficients of ex- } \\
\text { pansion }\end{array}$} \\
\hline & & & & $\begin{array}{l}\text { Temper- } \\
\text { ature }\end{array}$ & Load \\
\hline $\begin{array}{l}\text { P1 } \\
\text { A1 } 1 \ldots \\
\text { B1 } 12 \\
\text { B1 } 12 \\
\text { S2 } \\
\text { L3 }\end{array}$ & 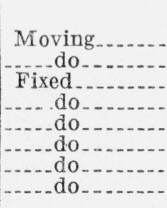 & $\begin{array}{l}\text { Copper wire } \\
\text { Aluminum ribbon } \\
\text { Copper wire } \\
\text { do }\end{array}$ & $\begin{array}{l}\begin{array}{l}\text { Pyrex glass } \\
\text { Aluminum alloy }\end{array} \\
\text { Brass }\end{array}$ & $\begin{array}{r}p p m /{ }^{\circ} C \\
4.1 \\
21.0 \\
21.1 \\
20.7 \\
17.0 \\
17.4 \\
17.6 \\
18.9\end{array}$ & $\begin{array}{r}p p m / w a t t \\
1.0 \\
0.0 \\
.11 \\
.08 \\
.35 \\
.50 \\
.30 \\
.61\end{array}$ \\
\hline
\end{tabular}

The temperature coefficient of each moving coil was determined directly by measuring with a micrometer a diameter at two different temperatures, usually $20^{\circ}$ and $30^{\circ} \mathrm{C}$. The glass coil, P1, was measured with the micrometer as used to determine its diameter, so that the measuring force was $300 \mathrm{~g}$. However, for the coil of aluminum strip, A1, the micrometer was modified by using spherical surfaces for its measuring faces and by reducing the measuring force to less than $20 \mathrm{~g}$. 
The temperature coefficients of the moving coils were also determined by the same method as used for the fixed coils. In this case the temperature of the moving coil was changed by changing the temperature of the room, and the temperature of the fixed coil was kept approximately constant by means of the water circulating through it. The values by the two methods agreed within experimental error, but those obtained by direct measurement were the more accurate.

The load coefficients of the moving coils are not important, since in them the same load was used in the current balance as in the measurement of the ratio of radii. The load coefficients of B1 and B2, the new fixed coils of aluminum strip, were less than one-third of that of the older fixed coils. This decrease resulted from the improved thermal contact between the form and the current-carrying parts of the coil.

\section{LENGTH OF THE MAGNET}

In all the measurements of the ratio of the radii, the over-all length of the magnet was $1.41 \mathrm{~mm}$ and the distance between poles was 1.13 $\mathrm{mm}$. The corrections were computed by eq 46 of the previous paper. The values were between 9 and 12 parts per million.

\section{EFFECT OF THE CROSS-SECTIONAL DIMENSIONS OF THE COILS}

The cross-sectional dimensions of a coil introduce a correction term in computing the ratio of its radius to that of another coil. This correction is required, because the magnetic field at the center of the coil is dependent on its cross-sectional dimensions as well as on its mean radius. As shown in appendix I, the magnetic field at the center of a coil of radius $a$ and of rectangular cross section with the axial dimension $2 b$ and radial dimension $2 c$ is, to an accuracy of 1 part in a million for all coils used in this investigation, represented by the equation

$H=\frac{2 \pi n I}{a}\left(1-\frac{b^{2}}{2 a^{2}}+\frac{c^{2}}{3 a^{2}}+\frac{3 b^{4}}{8 a^{4}}+\frac{c^{4}}{5 a^{4}}-\frac{b^{2} c^{2}}{a^{4}}-\frac{5 b^{6}}{16 a^{6}}+\ldots\right)=\frac{2 \pi n I}{a}(1-\Delta)$.

This equation differs from the similar equation given in the previous publication (eq 48, page 707) by the addition of the sixth-degree term in the series. For the solenoidal moving coil, this new term had a value of $0.5 \times 10^{-6}$. For all the other coils, it was entirely negligible. Values of $\Delta$ are given in table 9 .

\section{TABLE 9.-Dimensions of coils and the corrections for cross-sectional dimensions in measuring the ratio of radii}

[The correction to a coil is required in order to determine its mean radius from the number of turns in it and from the magnetic field produced at its center by unit current in its winding.]

\begin{tabular}{|c|c|c|c|c|c|c|}
\hline Designation of coil & $\begin{array}{l}\text { Num- } \\
\text { ber of } \\
\text { wind- } \\
\text { ings }\end{array}$ & $\begin{array}{c}\text { Num- } \\
\text { ber of } \\
\text { turns in } \\
\text { each } \\
\text { winding }\end{array}$ & Radius $=a$ & $\underset{2 b}{\text { Axial }}=$ & $\underset{2 c}{\text { Radial }}$ & $\begin{array}{l}\text { Correction } \\
\text { for cross- } \\
\text { sectional } \\
\text { dimensions } \\
=\Delta\end{array}$ \\
\hline $\begin{array}{l}\text { P1 } \\
\text { B1 } \\
\text { B2 } \\
\text { S1 } \\
\text { S2 }\end{array}$ & $\begin{array}{l}1 \\
2 \\
2 \\
2 \\
2 \\
2 \\
2 \\
2\end{array}$ & $\begin{array}{r}41 \\
45 \\
125 \\
125 \\
392 \\
392 \\
647 \\
647\end{array}$ & $\begin{array}{l}c m \\
12.2304 \\
12.5761 \\
22.664 \\
22.672 \\
19.97 \\
19.96 \\
25.00 \\
25.00\end{array}$ & $\begin{array}{l}c m \\
2.6650 \\
0.6364 \\
2.5398 \\
2.5397 \\
1.580 \\
1.579 \\
1.969 \\
1.965\end{array}$ & $\begin{array}{l}c m \\
0.0512 \\
.6521 \\
2.6236 \\
2.6373 \\
1.528 \\
1.522 \\
1.943 \\
1.925\end{array}$ & $\begin{array}{r}p p m \\
5881 \\
96 \\
458 \\
445 \\
295 \\
298 \\
273 \\
279\end{array}$ \\
\hline
\end{tabular}


With the new coils the correction for cross-sectional dimensions is, except for A1, larger than for the older coils. However, the cross sections of the new coils were measured with so much greater accuracy that the error on this account was much less than for the older coils.

\section{RESULTS}

The results of the measurements on the ratio of radii are given in table 10. The average deviation of a single observation from the mean of its group is in every case small, the maximum for all the groups being 4 parts per million. The adjusted values of the ratio of the radii, which were obtained as explained in the heading of the table, were used in computing the absolute value of the current.

As a further test of the reliability of the values of the ratio of radii, the ratio of the radii of the two moving coils has been computed, using each of the fixed coils as intermediary. The results are given in table 11. The average variation from the mean is 5 parts per million. However, this agreement does not of necessity indicate that each ratio is known with the indicated accuracy. If an error had been made in the measurement of the cross-sectional dimensions of a moving coil, or even in the computation of the correction factor from its dimensions, this would not affect the value of the ratio A1: P1.

\section{TABLE 10.-Ratio of radii of the various coil combinations}

IThe observed values of the ratio of the radii were those obtained by the electromagnetic method, when they were corrected to $22^{\circ} \mathrm{C}$ and no load. From each pair of values which involve the same fixed coil, a value can be obtained for the ratio of radii $\mathrm{A} 1: \mathrm{P} 1$ as given in table 11. The adjusted values, given in the last column, were obtained from each pair of observed values that involved a single fi xed coil. The same amount was added to one observed value as was subtracted from the other, in order that the ratio of A1:P1 as obtained from these adjusted values would be the same as the average value of A1:P1 as obtained from the observed values using all the fixed coils. In the case of fixed coil L3, the data for A1:L3 were less reliable than the data for P1:L3, so that the ratio A1:L3 was given twice as large an adjustment as was given to P1:L3.]

\begin{tabular}{|c|c|c|c|c|c|}
\hline Moving coil & $\begin{array}{l}\text { Fixed } \\
\text { coil }\end{array}$ & $\begin{array}{l}\text { Number } \\
\text { of ob- } \\
\text { serva- } \\
\text { tions }\end{array}$ & $\begin{array}{l}\text { Observed } \\
\text { ratio of } \\
\text { radii }\end{array}$ & $\begin{array}{l}\text { Devia- } \\
\text { tion from } \\
\text { mean }\end{array}$ & $\begin{array}{l}\text { Adjusted } \\
\text { ratio of } \\
\text { radii }\end{array}$ \\
\hline P1..... & $\left\{\begin{array}{l}\text { B1 } \\
\text { B2 } 1 \ldots \ldots \\
\text { S1 } \\
\text { S2 } \\
\text { L3 } 3 \ldots \ldots \\
\text { L4 } \ldots \ldots \ldots\end{array}\right.$ & $\begin{array}{r}7 \\
13 \\
5 \\
9 \\
7 \\
4\end{array}$ & $\begin{array}{r}0.5393497 \\
.5390832 \\
.6125251 \\
.6128091 \\
.4894701 \\
.4893822\end{array}$ & $\begin{array}{r}\text { ppm } \\
\pm 1 \\
2 \\
2 \\
2 \\
1 \\
1\end{array}$ & $\begin{array}{r}0.5393505 \\
.5390814 \\
.6125231 \\
.6128099 \\
.4894714 \\
.4893820\end{array}$ \\
\hline Al............. & $\left\{\begin{array}{l}\text { B1 } \\
\text { B2 } \\
\text { S1 } \\
\text { S2 } \\
\text { L3 } 3 \ldots \ldots \\
\text { L4 }\end{array}\right.$ & $\begin{array}{r}19 \\
9 \\
11 \\
8 \\
7 \\
4\end{array}$ & $\begin{array}{l}.5545363 \\
.5542569 \\
.6297661 \\
.6300638 \\
.5032552 \\
.5031601\end{array}$ & $\begin{array}{l}3 \\
2 \\
3 \\
3 \\
4 \\
4 \\
2\end{array}$ & $\begin{array}{l}.5545354 \\
.5542587 \\
.6297681 \\
.6300629 \\
.5032520 \\
.5031601\end{array}$ \\
\hline
\end{tabular}

- These measurements include 7 runs which were made with the 2 windings of B1 connected in series. These series results were corrected for the leakage caused by the insulation resistance between turns (see table 7). The mean of the series results, taken separately, differed by less than 1 part in a million from the mean of the results taken with the usual parallel connection of the windings.

b 6 measurements taken before the short-circuit occurred gave an average value of 0.5390829 , and 7 measurements taken after the compensating resistors had been installed (see footnote 8 ) gave an average value of 0.5390835 . Measurements after the short-circuit had been discovered and before the compensating resistors had been installed gave values 42 parts per million lower than the average. 
TABLE 11.-Computed ratio of the radii of the moving coils, using each fixed coil as intermediary

\begin{tabular}{|c|c|c|}
\hline Intermediary fixed coil & $\begin{array}{c}\text { Ratio of radii } \\
\mathrm{A} 1: \mathrm{P} 1\end{array}$ & $\begin{array}{l}\text { Deviation } \\
\text { from mean }\end{array}$ \\
\hline 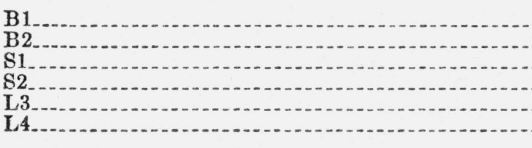 & $\begin{array}{r}1.028157 \\
147 \\
147 \\
157 \\
163 \\
154\end{array}$ & $\begin{array}{l}+3 \\
-7 \\
-7 \\
+3 \\
+9 \\
0\end{array}$ \\
\hline A verage & 1. 028154 & \pm 5 \\
\hline
\end{tabular}

\section{EXPERIMENTAL DETERMINATION OF THE MAXIMUM FORCE BETWEEN THE COILS}

The procedure for determining the maximum force was essentially the same as described in the previous paper. The moving coil was suspended from one arm of a sensitive balance. Two fixed coils having diameters about double that of the moving coil were mounted one above, the other below the moving coil. The planes of the three coils were made horizontal by means of sensitive levels, and their coaxiality was checked by electrical measurements with the balance itself. The distance between the fixed coils was that at which the force per unit current on the moving coil was the maximum that could be obtained with this set of coils. In this position there were measured both the sum of the forces of the two fixed coils on the moving coil and their difference. When the moving coil was connected in series with the fixed coils, the procedure in making the measurements of force and in adjusting the coils was the same as described in the previous paper. When the moving coil was in parallel with the fixed coils, as shown in figure 9 , the procedure for making a measurement required not only the reading of the swings of the balance but also the frequent adjustment of the two resistors by which the currents in the fixed and the moving coils were maintained constant.

The measurement of the force and the adjustment of the coils was carried out in the same manner as previously described. Also, the difference of the forces was regularly measured to make the necessary corrections for lack of perfect adjustment of the coils. This measured difference of the forces was compared with the computed difference of the forces as a check on the computations. As the check was satisfactory in every case, detailed values are not given.

\section{SOURCES OF ERROR AND CORRECTIONS}

Thirteen different sources of error were discussed in the previous publication. Only five of them will be discussed here, since for eight of them-the adjustment of the coils, the sensitivity of the balance, the weights and buoyancy correction, the lead correction, the changes in rest point, convection currents in the air, the presence of magnetic bodies, and the effect of external magnetic fields-the same considerations hold now as formerly. The sum of the maximum uncertainties which were assigned to these eight sources was between 7 and 12 parts per million in the current. As all of these which may have produced an appreciable effect were accidental errors, the average result from 
a number of observations would probably not be influenced by any of them.

In addition to the 13 sources of error previously considered, there is the question, already discussed, of the insulation resistance when the windings of the fixed coils of aluminum ribbon were connected in series and the possibility that, in the coils of aluminum ribbon, the current distribution was affected by the magnetic field. Such a change in distribution would be produced by the Hall effect. However, a mathematical analysis ${ }^{12}$ showed that the effect on the force was much less than 1 part in a million and might be zero.

The only other variation from uniform current distribution was the absence of current in the insulation between the turns. Although this insulation in the aluminum-ribbon coils was only 4 to $6 \mu$ in thickness, the insulation occupied about 10 percent of the cross section. However, this lack of uniformity produced a negligible effect on the computed current, since the magnetic intensity produced by a current in a ribbon at a point which is farther from the center of the ribbon than its width is, to a high degree of approximation, independent of the thickness of the ribbon.

\section{(a) ACCELERATION OF GRAVITY}

The value of gravity has been taken as $980.095 \mathrm{~cm} / \mathrm{sec}^{2}$, the same as in the previous work. This was based on the value of $981.274 \mathrm{~cm} / \mathrm{sec}^{2}$ at Potsdam. However, absolute determinations ${ }^{13}$ made at the National Bureau of Standards and the National Physical Laboratory, since the previous publication, gave values 20 parts per million and 13 parts per million, respectively, lower than the one derived from the Potsdam value. While this must be considered in arriving at a value of the ampere which will be used to fix the electrical units, yet comparisons with previous determinations and those of other laboratories are facilitated by using for the present the old value of gravity.

\section{(b) TEMPERATURE OF THE COILS}

The temperature of the coils introduced a larger correction with some of the new coils than with those formerly used. The reason is that the correction involves the difference of the temperature coefficients as well as the differences in temperatures of the two coils from the standard temperature $\left(22^{\circ} \mathrm{C}\right)$. As the temperature coefficients of the new coils were carefully determined, and the temperatures were obtained during every observation by measuring the resistance of the winding, the error of a single observation resulting from the temperature correction was about the same as formerly; namely, 2 parts per million.

\section{(c) ELECTRICAL LOAD ON THE COILS}

The effect of the electrical load was much less for the new coils than for the older ones. With the moving coils, the same load was used in the current balance as in measuring the ratio of the radii. Hence, no correction for load was required for these coils. For the fixed coils of aluminum ribbon, the load coefficients were so small that the maximum correction on this account was only 3 parts per million. The

12 This analysis was carried out by C. Snow.

${ }^{13}$ Heyl and Cook, The value of gravity at Washington, J. Research NBS 17, 805 (1936) RP946: Clark, An absolute determination of the acceleration due to gravity. Roy. Soc. Phil. Trans. (London) 238A, 65 (1939). 
error in applying this correction was probably less than 1 part in a million for the new coils, whereas it may have been as large as 3 parts in a million for the older fixed coils.

\section{(d) EFFECT OF ERRORS IN THE MEASUREMENT OF THE CROSS SECTIONS OF THE COILS}

The effect on the measured force of errors in the measured cross sections of the coils was computed by eq 57 of the previous paper. The results are given in table 12 , which, for convenience of comparison, includes data on the coils used in the previous investigation. The estimated uncertainty of $20 \mu$ for the half-sectional dimension of each of the old coils is twice that given in the previous paper, since a reexamination of the original data shows that this is a more probable estimate. For the new coils, the corresponding estimated uncertainty in the measured dimensions is one-half the average deviation of each group of observations from the mean of all the groups. Since the sign of each computed error cannot be known, the maximum error resulting from these estimated uncertainties is the sum of the individual errors, but the square root of the sum of the squares is a more useful method of comparing results as it is proportional to the probable error.

TABLE 12.-Effect of estimated uncertainties in the measured dimensions of the cross sections of the coils on the computed force

\begin{tabular}{|c|c|c|c|c|c|c|c|c|c|c|c|}
\hline \multirow{2}{*}{ Fixed coil } & \multicolumn{2}{|c|}{$\begin{array}{l}\text { Estimated un- } \\
\text { certainty a in } \\
\text { cross-sectional } \\
\text { dimensions }\end{array}$} & \multirow{2}{*}{$\begin{array}{l}\text { Mov- } \\
\text { ing } \\
\text { coil }\end{array}$} & \multicolumn{2}{|c|}{$\begin{array}{l}\text { Estimated un- } \\
\text { certainty in } \\
\text { cross-sectional } \\
\text { dimensions }\end{array}$} & \multicolumn{6}{|c|}{$\begin{array}{c}\text { Computed b error in } F \text { from estimated un. } \\
\text { certainties }\end{array}$} \\
\hline & $\underset{\delta b_{1}}{\text { Axial }}$ & $\underset{\delta c_{1}}{\text { Radial }}$ & & $\underset{\delta b_{2}}{\text { Axial }}$ & $\underset{\delta c_{2}}{\text { Radial }}$ & $b_{1}$ & $c_{1}$ & $b_{2}$ & $c_{2}$ & $\begin{array}{l}\text { Maxi- } \\
\text { mum for } \\
\text { coil com- } \\
\text { bination }\end{array}$ & $\begin{array}{l}\text { Square } \\
\text { root of } \\
\text { sum of } \\
\text { squares }\end{array}$ \\
\hline $\begin{array}{l}\mathrm{S} 1 \text { or } \mathrm{S} 2 \\
\mathrm{~L} 3 \text { or } \mathrm{L} 4 \ldots . . . . .\end{array}$ & $\begin{array}{r}\mu \\
20 \\
20\end{array}$ & $\begin{array}{r}\mu \\
20 \\
20\end{array}$ & M2 & ${ }^{\mu} 20$ & ${ }^{\mu} 20$ & $\left\{\begin{array}{r}p p m \\
4.8 \\
2.0\end{array}\right.$ & $\begin{array}{r}p p m \\
4.8 \\
2.0\end{array}$ & $\begin{array}{l}\text { ppm } \\
30 \\
21\end{array}$ & $\begin{array}{r}p p m \\
30 \\
21\end{array}$ & $\begin{array}{r}p p m \\
\pm 69 \\
46\end{array}$ & $\begin{array}{r}p p m \\
\quad \pm 43 \\
\quad 30\end{array}$ \\
\hline $\begin{array}{l}\text { S1 or } \mathrm{S} 2 \ldots \ldots \\
\mathrm{L} 3 \text { or } \mathrm{L} 4 \ldots \ldots\end{array}$ & $\begin{array}{l}20 \\
20\end{array}$ & $\begin{array}{l}20 \\
20\end{array}$ & M3 & 20 & 20 & $\left\{\begin{array}{l}2.4 \\
2.2\end{array}\right.$ & $\begin{array}{l}2.4 \\
1.2\end{array}$ & $\begin{array}{l}33 \\
26\end{array}$ & $\begin{array}{l}33 \\
26\end{array}$ & $\begin{array}{l}71 \\
54\end{array}$ & $\begin{array}{l}47 \\
37\end{array}$ \\
\hline $\begin{array}{l}\mathrm{B} 1 \text { or } \mathrm{B} 2 \\
\mathrm{~S} 1 \text { or } \mathrm{S} 2 \\
\mathrm{~L} 3 \text { or } \mathrm{L} 4\end{array}$ & $\begin{array}{r}5 \\
20 \\
20\end{array}$ & $\begin{array}{l}15 \\
20 \\
20\end{array}$ & P1 & 0.5 & 0.5 & $\left\{\begin{array}{l}1.0 \\
5.0 \\
1.5\end{array}\right.$ & $\begin{array}{l}3.0 \\
5.0 \\
1.5\end{array}$ & $\begin{array}{l}1.5 \\
2.0 \\
1.5\end{array}$ & $\begin{array}{l}0 \\
0 \\
0\end{array}$ & $\begin{array}{r}5.5 \\
12.0 \\
4.5\end{array}$ & $\begin{array}{l}3 \\
7 \\
3\end{array}$ \\
\hline $\begin{array}{l}\mathrm{B} 1 \text { or } \mathrm{B} 2 \\
\mathrm{~S} 1 \text { or } \mathrm{S} 2 \\
\mathrm{~L} 3 \text { or } \mathrm{L} 4\end{array}$ & $\begin{array}{r}5 \\
20 \\
20\end{array}$ & $\begin{array}{l}15 \\
20 \\
20\end{array}$ & A1 & 2.5 & 10 & $\left\{\begin{array}{l}1.0 \\
5.0 \\
1.0\end{array}\right.$ & $\begin{array}{l}\text { 3. } 0 \\
5.0 \\
1.0\end{array}$ & $\begin{array}{l}2.0 \\
2.5 \\
2.0\end{array}$ & $\begin{array}{r}8 \\
10 \\
7\end{array}$ & $\begin{array}{l}14.0 \\
22.5 \\
11.0\end{array}$ & $\begin{array}{r}9 \\
12 \\
7\end{array}$ \\
\hline
\end{tabular}

- Values given in these columns are one-balf the estimated uncertainty of the cross-sectional dimensions in order that they may be used directly in the equation for computing the error in $F$.

b This error was computed by eq 57, page 724, of the previous publication.

(e) SUMMARY OF ESTIMATED ACCIDENTAL ERRORS IN DETERMINING THE ABSOLUTE VALUE OF THE CURRENT

A summary giving the effect on the absolute value of the current of the estimated uncertainty from each of the sources of error to which a value of the average deviation can be assigned is given in table 13. Of these sources, the acceleration of gravity is common to all the observations. The finite cross section of the coils was the largest source of error for most observations, but the changes in rest point gave, with some sets of coils, as large an error when the force was very small. 
The resultant effect of the errors is different for each of the different combinations of coils. The resultant uncertainty for each combination of the coils lies between 4 and 24 parts per million.

In the observations with a given current and set of coils, the differences between individual runs were the result of only four of the sources of error listed in table 13; namely, adjustment of coils, sensitivity of balance, temperature of coils, and changes in rest point. Using the values given in the table, the probable uncertainty of an individual value from the mean of the set is 5 parts per million. This estimated value is in good agreement with the observed values given in the last column of table 14, which are the average deviations of a single observation from the mean of the group. The observed values include not only the uncertainties in the absolute value of the current, but also those connected with the measurement of the current in NBS international amperes. These latter uncertainties were estimated to be less than 2 parts in a million, since they involved only standard cells, standard resistors, and a very simple measuring circuit.

TABLE 13.-Summary of sources of error in the absolute measurement of current and estimates of their maximum magnitudes

\begin{tabular}{|c|c|}
\hline Sources of error & $\begin{array}{l}\text { Effect on } \\
\text { value of } \\
\text { current of } \\
\text { probable } \\
\text { uncertain- } \\
\text { ties }\end{array}$ \\
\hline & $p p m$ \\
\hline $\begin{array}{l}\text { Adjustment of coils } \\
\text { Sensitivity of balance }\end{array}$ & $<$ \\
\hline Weights and buoyaney correction & \\
\hline Acceleration of gravity & 2 \\
\hline Ratio of radii & 4 \\
\hline Temperature of the coils & 2 \\
\hline Electrical load coefficient of the coils b old fixed coils & 5 \\
\hline Legd correction $\quad$ lnew fixed coils........ & \\
\hline Changes in rest point & 2 to 7 \\
\hline Convection currents in the air & $<i$ \\
\hline Magnetic bodies & $<1$ \\
\hline External magnetic fields & $<1$ \\
\hline Finite cross section of coils b & c 4.5 to 22 \\
\hline Insulation resistance when windings of $\mathrm{B} 1$ and $\mathrm{B} 2$ are in series. & 2 \\
\hline
\end{tabular}

a The value used was the same as in the previous work, namely. $980.095 \mathrm{~cm} / \mathrm{sec}^{2}$ at the beam of the balance. The error given is concerned only with the transfer from Potsdam to Washington.

b Value given is different from that in previous paper.

- See table 12 .

In addition to accidental errors, there are systematic errors which can be estimated only by comparing the results with the different sets of coils. This comparison will be made when discussing the results of all the measurements.

\section{VALUE OF A CURRENT IN NBS INTERNATIONAL AMPERES AND IN ABSOLUTE AMPERES}

The value, in absolute amperes, of a current having a value of 1 NBS international ampere has been obtained for six combinations of coils. The results, expressed in the form $\left(I_{N B S}-I_{a}\right) / I_{a}$, are given in table 14 for all of these combinations, where $I_{N B S}$ is the value of the current in NBS international amperes and $I_{a}$ is the value of the current in absolute amperes. In the table are also given the nominal values of the measured force and of the currents in the coils. 
TABLE 14.-Summary of the results on the absolute determination of the ampere

\begin{tabular}{|c|c|c|c|c|c|c|c|c|}
\hline \multirow{2}{*}{ Date } & \multirow{2}{*}{$\begin{array}{c}\text { Moving } \\
\text { coil }\end{array}$} & \multirow{2}{*}{$\begin{array}{l}\text { Fixed } \\
\text { coils }\end{array}$} & \multirow{2}{*}{$\begin{array}{l}\text { Approxi- } \\
\text { mate } \\
\text { force in } \\
\text { grams }\end{array}$} & \multicolumn{2}{|c|}{$\begin{array}{l}\text { Approximate } \\
\text { current }\end{array}$} & \multirow{2}{*}{$\begin{array}{l}\text { No. of } \\
\text { obser- } \\
\text { vations } \\
\text { in } \\
\text { group }\end{array}$} & \multirow{2}{*}{$\frac{I_{N B S}-I_{a}}{I_{a}}$} & \multirow{2}{*}{$\begin{array}{l}\text { A ver- } \\
\text { age } \\
\text { devia- } \\
\text { tion } \\
\text { from } \\
\text { mean } \\
\text { of } \\
\text { group }\end{array}$} \\
\hline & & & & $\begin{array}{c}\text { Moving } \\
\text { coil }\end{array}$ & $\begin{array}{l}\text { Fixed } \\
\text { coil }\end{array}$ & & & \\
\hline \multirow[b]{2}{*}{$\left.\begin{array}{l}\text { May } 1935 \\
\text { June } 1935 \\
\text { Dec. } 1936 \\
\text { May and June } 1937\end{array}\right\}$} & \multirow[b]{2}{*}{$\begin{array}{l}\mathrm{P} 1 \\
\mathrm{A1}\end{array}$} & \multirow[b]{2}{*}{$\begin{array}{l}\mathrm{S} 1, \mathrm{~S} 2 \\
\mathrm{~S} 1, \mathrm{~S} 2\end{array}$} & \multirow[b]{2}{*}{$\begin{array}{l}6.26 \\
2.78 \\
7.60 \\
3.38\end{array}$} & $\begin{array}{l}\text { Am- } \\
\text { peres }\end{array}$ & $\begin{array}{l}\text { Am- } \\
\text { peres }\end{array}$ & \multirow[b]{2}{*}{$\begin{array}{r}11 \\
3 \\
5 \\
9\end{array}$} & \multirow[b]{2}{*}{$\begin{array}{l}p p m \\
101 \\
102 \\
79 \\
80\end{array}$} & \multirow[b]{2}{*}{$\begin{array}{r}p p m \\
\pm 3 \\
3 \\
2 \\
8\end{array}$} \\
\hline & & & & \multicolumn{2}{|c|}{$\begin{array}{r}1.02 \\
.68 \\
1.02 \\
.68\end{array}$} & & & \\
\hline \multicolumn{7}{|c|}{$\begin{array}{l}\text { A verage with coils } S 1 \text { and } S 2 \\
\text { A verage deviation of the mean of each group from the mean of all the groups in } \\
\text { which coils } S 1 \text { and } S 2 \text { were used }\end{array}$} & $\begin{array}{r}90 \\
\pm 11\end{array}$ & $(-10$ \\
\hline $\begin{array}{l}\text { Feb. and Mar. 1936. } \\
\text { Do } \\
\text { May and June 1936 } \\
\text { Do }\end{array}$ & $\begin{array}{l}\text { P1 } \\
\text { A1 }\end{array}$ & $\begin{array}{l}\mathrm{L} 3, \mathrm{~L} 4 \\
\mathrm{~L} 3, \mathrm{~L} 4\end{array}$ & $\begin{array}{l}5.67 \\
2.52 \\
6.71 \\
2.98\end{array}$ & \multicolumn{2}{|c|}{$\begin{array}{r}1.02 \\
.68 \\
1.02 \\
.68\end{array}$} & $\begin{array}{r}19 \\
24 \\
11 \\
9\end{array}$ & $\begin{array}{l}123 \\
118 \\
108 \\
118\end{array}$ & $\begin{array}{r} \pm 4 \\
8 \\
4 \\
11\end{array}$ \\
\hline \multicolumn{7}{|c|}{$\begin{array}{l}\text { Average with coils L3 and L4 } \\
\text { Averege deviation of the mean of each group from the mean of all the groups in } \\
\text { which coils } L 3 \text { and } L 4 \text { were used. }\end{array}$} & $\begin{array}{l}117 \\
\pm 4\end{array}$ & 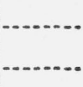 \\
\hline $\begin{array}{l}\text { June 1938. } \\
\text { Do } \\
\text { Aug. and Sep. 1938 } \\
\text { Sept. } 1938\end{array}$ & \multirow[t]{2}{*}{$\begin{array}{l}\text { A1 } \\
\text { P1 }\end{array}$} & \multirow[t]{2}{*}{$\begin{array}{l}\mathrm{B} 1, \mathrm{~B} 2 \\
\mathrm{~B} 1, \mathrm{~B} 2\end{array}$} & \multirow{2}{*}{$\begin{array}{r}.3 .35 \\
1.67 \\
\times 2.81 \\
1.40 \\
7.03 \\
2.81\end{array}$} & \multicolumn{2}{|c|}{$\begin{array}{l}1.02 \\
1.02 \\
1.02 \\
1.02\end{array}$} & \multirow{2}{*}{$\begin{array}{r}9 \\
6 \\
6 \\
11 \\
9 \\
4\end{array}$} & \multirow{2}{*}{$\begin{array}{l}147 \\
147 \\
148 \\
151 \\
148 \\
149\end{array}$} & \multirow{2}{*}{$\begin{array}{r} \pm 0 \\
3 \\
3 \\
6 \\
2 \\
3\end{array}$} \\
\hline $\begin{array}{l}\text { Sept. and Oct. } 1938 \\
\text { Oct. } 1938\end{array}$ & & & & $\begin{array}{l}1.02 \\
.4\end{array}$ & $\begin{array}{l}5.09 \\
5.09\end{array}$ & & & \\
\hline $\begin{array}{l}\text { Average with coils } B 1 \\
\text { Average deviation of } t \\
\text { which coils } B 1 \text { and } \mathrm{B}\end{array}$ & $\begin{array}{l}1 \text { and } \mathrm{B} 2 \\
\text { the mear } \\
\mathrm{B} 2 \text { were }\end{array}$ & ed each g & up from m & nean of & 1 the & ups in & $\begin{array}{l}148 \\
\pm 1\end{array}$ & \\
\hline
\end{tabular}

- The windings of the fixed coils were connected in series which doubled the number of turns and there fore the heating effects and the force. A correction of 3 parts in a million was made for leakage currents.

\section{DISCUSSION OF RESULTS}

The discussion of results is for the purpose of indicating the uncertainty that may exist in the result when any coil or combination of coils was used. A summary of all the results obtained in this and the previous investigation is given in table 15 . In analyzing the sources of error in a previous section, it was shown that the uncertainty in a result was largely caused either by uncertainties in the cross-sectional dimensions of the coils that were used or by systematic errors that can be detected only when comparing the results from different sets of coils. Hence, this discussion will be mainly concerned with these questions, since the result with any set of coils could be repeated within a few parts in a million (see table 14).

The construction of the older coils is such that the cross sections cannot be remeasured, so that it is necessary to depend on the values obtained when they were constructed some 30 years ago. The coils made for the present investigation were so designed and constructed that the cross-sectional dimensions could be accurately measured and can be remeasured whenever necessary. 
Each of the fixed coils, S1 and S2, had 28 layers of wire, and the wires were brought up from one layer to the next on the same diameter, so that, as stated in the earlier work, "the winding became elliptical with the long axis along this diameter." This ellipticity was important mainly because it affected the cross section. As a result, the correction for cross section was quite uncertain. This uncertainty was confirmed by the variability in the results with this pair of fixed coils (column 1 of table 15) when used with different moving coils. For these reasons all the results when using the fixed coils, S1 and S2, have been given zero weight.

TABLE 15.- Summary of all the results obtained in this and the previous investigation

\begin{tabular}{|c|c|c|c|c|}
\hline \multirow{2}{*}{$\begin{array}{l}\text { Moving } \\
\text { coils } \\
\downarrow\end{array}$} & \multirow[b]{2}{*}{ Pairs of fixed coils $\rightarrow$} & \multicolumn{3}{|c|}{ Values of $\left(I_{N B S}-I_{a}\right) / I_{a}$} \\
\hline & & S1, S2 & $\mathrm{L} 3, \mathrm{~L} 4$ & $\mathrm{~B} 1, \mathrm{~B} 2$ \\
\hline $\begin{array}{l}\mathrm{M} 2 \\
\mathrm{M} 3 \\
\mathrm{~A} 1 \\
\mathrm{P} 1\end{array}$ & 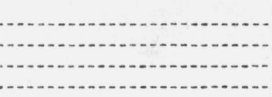 & $\begin{array}{l}10 \times 10^{-6} \\
53 \\
80 \\
102\end{array}$ & $\begin{array}{l}94 \times 10^{-6} \\
81 \\
113 \\
120\end{array}$ & $147 \times 10^{-6}$ \\
\hline
\end{tabular}

The uncertainties in the cross sections of the moving coils, M2 and M3, produced, as shown in table 12, a large uncertainty in the results obtained with these coils. The experimental results obtained with these coils (first and second rows of table 15) and only two of the sets of fixed coils show differences such as might be expected from large uncertainties in the cross-sectional dimensions. Moreover, the construction of these coils was similar to that of S1 and S2, so that the same kinds of systematic errors were undoubtedly present as have been deemed sufficient to give all results obtained with $\mathrm{S} 1$ and S2 a weight of zero. Hence these three lines of evidence indicate that the results using the moving coils, M2 and M3, should be given very little weight. They have not been used in determining the weighted mean.

Fixed coils L3 and L4, while wound with 36 layers of wire, were made so as to avoid the ellipticity that occurred in S1, S2, M2, and M3. The method of winding was described in the earlier publication as follows: "The wire was brought up from one layer to the next at a point one thirty-sixth of a revolution short of the point at which it was brought up the layer before. Thus the coil is kept circular and each winding has one turn less than by the old method." Although this method of winding increased the uniformity of radial depth, it introduced an uncertainty concerning the current distribution, since a part of a turn was lacking in every layer. However, these coils were $50 \mathrm{~cm}$ in diameter, whereas $\mathrm{S} 1$ and $\mathrm{S} 2$ were only $40 \mathrm{~cm}$, and the increase in diameter made a knowledge of the cross section less important. These conclusions concerning the reliability of coils L3 and L4 are substantiated by the results which were obtained when using them with different moving coils ( $2 \mathrm{~d}$ column of table 15). Hence, those results obtained with L3 and L4 and the moving coils, $\mathrm{P} 1$ and $\mathrm{A1}$, have been retained.

The moving coils, P1 and A1, had quite different cross-sectional shapes, yet both met the requirements imposed in deriving the formula for computing the absolute value of the current. Because of the difference in shape, there seems to be little chance of a common source 
of systematic errors. While the results for A1 (3d row of table 15) are, for corresponding pairs of fixed coils, somewhat lower than those for P1 (4th row), yet these differences are probably all the result either of uncertainties in the fixed coils or of experimental errors. No sufficient reason has been found for weighting the results obtained with one coil differently from those obtained with the other coil.

Fixed coils B1 and B2 more nearly conformed to the theoretical requirements than did the coils L3 and L4. Only in two respects. was there a measurable deviation from the cross section postulated in deriving the theory. The edges of the ribbon did not all lie in a plane perpendicular to the axis of the coil, but formed a series of steps. The effect of this was shown to be negligible. Also, the ribbon was slightly longer at the edges than at the centel, so that the outside layers of the coil were concave outwards. This necessitated taking an average radial depth, but the uncertainty in this did not introduce an uncertainty of more than 1 or 2 parts in a million in the result. After considering the facts, the authors have arbitrarily given the results with B1 and B2 (last column of table 15) twice the weight of those with L3 and L4.

The computation of the weighted mean of the results is given in table 16. Those that have been given zero weight are not included

$\mathrm{T}_{\mathrm{ABLE}}$ 16.-Evaluation of the weighted mean of all the results which have not been discarded

\begin{tabular}{|c|c|c|c|c|c|}
\hline Fixed coils & $\begin{array}{c}\text { Moving } \\
\text { coil }\end{array}$ & $\frac{I_{N B S}-I_{a}}{I_{a}}$ & $\begin{array}{l}\text { Ratio of the } \\
\text { value of a cur- } \\
\text { rent in absolute } \\
\text { amperes to the } \\
\text { value in NBS } \\
\text { international } \\
\text { amperes }\end{array}$ & Weight & $\begin{array}{c}\text { Deviation } \\
\text { from } \\
\text { weighted } \\
\text { mean }\end{array}$ \\
\hline L3, L4 & $\left\{\begin{array}{l}\mathrm{A} 1 \\
\mathrm{P} 1\end{array}\right.$ & $\begin{array}{r}p p m_{113} \\
120\end{array}$ & $\begin{array}{r}0.999887 \\
880\end{array}$ & $\stackrel{1}{1}$ & $\begin{array}{l}+25 \times 10^{-6} \\
+18\end{array}$ \\
\hline $\mathrm{B} 1, \mathrm{~B} 2 \ldots$ & $\begin{array}{l}\mathrm{A} 1 \\
\mathrm{P} 1\end{array}$ & $\begin{array}{l}147 \\
149\end{array}$ & $\begin{array}{l}853 \\
851\end{array}$ & ${ }_{2}^{2}$ & $\begin{array}{l}-9 \\
-11\end{array}$ \\
\hline Weighted mean & & 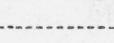 & 0.999862 & & $\pm 14 \times 10^{-6}$ \\
\hline
\end{tabular}

in this table. The weighted mean of this and the previous investigation is

\section{NBS international ampere $=0.99986$ absolute ampere}

However, the weighting had little effect on the result. If the results from both sets of fixed coils, which are given in table 16, had been given equal weight, the weighted mean would have been decreased by only 5 parts in a million, but if coils B1 and B2 had been given a weight of 5 , the increase would have been 5 parts per million.

The difference between this result and that previously published is 68 parts in a million. This difference now appears to be largely, if not entirely, the result of systematic errors in the previous investigation. There is no indication that there has been any drift in the NBS units of resistance or electromotive force on which the NBS international ampere is based. The systematic error resulted because the actual coils used in the previous investigation did not sufficiently 
well conform to the requirements imposed in developing the theoretical formulas. In the present investigation the probability of a systematic error affecting the results was greatly reduced by using two different types of moving coils and two diffirent types of fixed coils. The authors are convinced that the accidental errors of the present investigation have not introduced an error of as much as 20 parts per million in the final result.

From the results of the international comparison of standard resistors and standard cells at the International Bureau of Weights and Measures in 1937, the result here given can be expressed in mean international amperes. In order to indicate the difference between the two international amperes, it is necessary to carry results to six significant figures. Then

1 mean international ampere $\left\{\begin{array}{l}=1.000006 \text { NBS international ampere. } \\ =0.999868 \text { absolute ampere }\end{array}\right.$

The above values are based on the value of gravity as determined at Potsdam. Using the value of gravity recently obtained at the National Bureau of Standards,

1 mean international ampere $=0.999858$ absolute ampere.

\section{COMPARISON WITH RESULTS RECENTLY OBTAINED IN OTHER LABORATORIES}

Since the publication of the previous report, the results of three investigations in other laboratories have been published. The results, including the one from this paper, are given in table 17.

TABLE 17.-Recent results on the absolute value of the ampere

\begin{tabular}{|c|c|c|c|c|c|}
\hline Date & Laboratory & $\begin{array}{l}\text { Type of cur. } \\
\text { rent balance }\end{array}$ & $\begin{array}{l}\text { Published } \\
\text { value of } 1 \\
\text { national } \\
\text { ampere in } \\
\text { absolute } \\
\text { amperes }\end{array}$ & $\begin{array}{c}\text { Converted } 1 \\
\text { value: } 1 \text { mean } \\
\text { international } \\
\text { ampere in } \\
\text { absolute } \\
\text { amperes }\end{array}$ & $\begin{array}{l}\text { Published estimate of } \\
\text { uncertainty in result }\end{array}$ \\
\hline $1935 .$. & LCE (France) & Cotton......... & 0.9998 , & 1.0000 & $\begin{array}{l}\text { Several parts in } 10 \\
\text { thousand. }\end{array}$ \\
\hline $1936 \ldots$ & NPL (England) 3 & Ayrton-Jones . & .99986 & .99985 & 20 ppm. \\
\hline $1937 \ldots . .$. & ETL (Japan) & Rayleigh....... & .99994, & .99993 : & No estimate. ' \\
\hline $1939 \ldots$ & NBS (United States) & .....do & .999862 & .999868 & 20 ppm. \\
\hline
\end{tabular}

1 The published values in terms of national amperes were converted to mean international amperes by means of the values for the different national units as obtained by the International Bureau of Weights and Measures. The French conversion factor was obtained from the Procès-Verbaux for 1935; the conversion factor for the other nations from the Procès-Verbaux for 1937.

2 Dupouy and Jouaust, Sur la measure absolue des champs magnétique et la detérmination de l'ampère en value absolue, J. phys. radium [7] 6, 123 (1935)

3 Vigoureux, An absolute determination of the ampere, Roy. Soc. Phil. Trans. (London) 236A, 133 (1936);

Nat. Phys. Lab. Collected Researches 24, 173 (1938).
Yoneda and Ishibashi, Detérmination absolue du courant, Procès-Verbaux des Séances du Comité International des Poids et Mesures [2] 18, 185 (1937).

'The average deviation of the experimental result with each set of coils from the mean of all the sets is $\pm 37 \times 10^{-6}$.

The authors acknowledge help from many of their associates at the National Bureau of Standards, only a few of whom have been mentioned in this paper.

Washington, February 14, 1939. 


\section{APPENDIX I}

\section{An Addition to the Derivation of the Force Formula to Include Some Terms of the Sixth Degree in the Coil Dimensions}

\section{By Chester Snow}

The force between two coaxial circles carrying unit current is denoted by $\mathbf{F}(x, \alpha)$, where $x$ and $\alpha$ are two dimensionless independent variables, $\alpha$ being the ratio of the radii $a_{2} / a_{1}\left(a_{2}<a_{1}\right)$ and $x$ being $z / \sqrt{a_{1}^{2}+a_{2}^{2}}$, where $z$ is the distance between their planes. The force between actual coils of rectangular cross section carrying in each turn currents $I_{1}$ and $I_{2}$, respectively, is denoted by $\mathfrak{F}(x, \alpha)$, which depends on the current and number of turns in each coil and is proportional to $\mathrm{F}$ $(x, a)$, where $a_{1}$ and $a_{2}$ are the mean radii of the coils and $z$ is the distance between their mean planes. However, $\mathfrak{F}(x, a)$ also includes a factor which is only slightly different from unity and which is a function of the dimensionless ratios $b / a$ and $c / a$ for each of the two coils, where $2 b$ is the axial breadth and $2 c$ is the radial depth of the rectangular cross section of a coil of mean radius $a$.

In a previous paper ${ }^{14} \mathfrak{F}(x, a)$ was evaluated by assuming that the current was uniformly distributed over the cross section of the coil. In section $\mathrm{V}$ of that paper this assumption was shown to be a matter of convenience in reckoning only, provided that the effective ratio of the coils was measured by comparison of the magnetic fields at their centers, and also on the assumption that each wire was at the center of a square of such dimensions that the coil section was completely filled by these squares. With these assumptions the formula for the force may be put in the general form

$$
\mathfrak{F}(x, \alpha)=n_{1} n_{2} I_{1} I_{2} \mathrm{~F}(x, \alpha)\left\{1+\Delta_{2}(x, \alpha)+\Delta_{4}(x, \alpha)+\Delta_{6}(x, \alpha)\right\},
$$

where $n_{1}$ and $n_{2}$ are the number of turns in the coils, $I_{1}$ and $I_{2}$ are the currents in the coils, and $\Delta_{2}, \Delta_{4}$, and $\Delta_{6}$ are algebraic terms involving the four small ratios $b_{1} / a_{1}, c_{1} / a_{1}, b_{2} / a_{2}$, and $c_{2} / a_{2}$ to the degrees two, four, and six, respectively. Terms of odd degree do not appear in the formula, because the centroid of each coil section is, for convenience, taken as the origin of reference, about which the force is expanded by Taylor's theorem in four variables.

In the measurements reported in the previous paper by Curtis and Curtis, the four small ratios given above were all of the same order of magnitude and so small that terms of sixth degree were less than 1 part in a million. For this reason the term $\Delta_{6}$ has not previously been evaluated.

In the present paper there is described a new moving coil, $\mathrm{P} 1$, with a single layer whose axial width, $2 b_{2}$, is so much larger than any previous coil $(2.7 \mathrm{~cm}$ as compared with $1 \mathrm{~cm})$ that the evaluation of a small number of the many terms of sixth degree was required. The number was not excessive because of the small radial depth, $2 c$, which was only 0.1 that of the other coils.

\footnotetext{
16 Snow, BS J. Research 11, 681 (1933) RP615.
} 
By the same methods used in obtaining $\Delta_{2}$ and $\Delta_{4}$, it is found that all terms of importance in $\Delta_{6}$ are given by

$$
\Delta_{6}=\frac{b_{2}^{2}}{6 !}\left\{\left[\frac{b_{2}^{4}}{7}+b_{1}^{2} b_{2}^{2}+b_{1}^{4}\right] \frac{D_{2}^{6} F}{F}+c_{1}^{2}\left[b_{2}^{2}+\frac{10 b_{1}^{2}}{3}\right] \frac{D_{a_{1}}^{2} D_{z}^{4} F}{F}+c_{1}^{4} \frac{D_{a_{1}}^{4} D_{z}^{2} F}{F}\right\}
$$

Using the partial differential equation for $F$, these partial derivatives may all be expressed in terms of ordinary $x$-derivatives, as in the original derivation. The latter may then be expressed, as before, in terms of

$$
\lambda_{n}(x)=\frac{(-1)^{n+1} x^{n} F_{(x)}^{(n)}}{F},
$$

so that in addition to the $\lambda_{1}, \lambda_{2}, \lambda_{3}$, and $\lambda_{4}$ (defined in eq 12 of the paper listed in footnote 14) there are the two new ones

$$
\begin{aligned}
& \lambda_{5}=\frac{x^{2}\left[-75 x^{2} \lambda_{1}+213 x^{2} \lambda_{2}-\left(117 x^{2}+40\right) \lambda_{3}+20\left(x^{2}+1\right) \lambda_{4}\right]}{x^{4}+2 x^{2}+\beta^{2}} \\
& \lambda_{6}=\frac{x^{2}\left[-288 x^{2} \lambda_{2}+447 x^{2} \lambda_{3}-\left(177 x^{2}+60\right) \lambda_{4}+24\left(x^{2}+1\right) \lambda_{5}\right]}{x^{4}+2 x^{2}+\beta^{2}}
\end{aligned}
$$

In computing the $\lambda$ 's by these formulas, $\lambda_{1}=0$ for the position of maximum force. Equation 5 becomes

$$
\begin{aligned}
\Delta_{0}= & \frac{-b_{2}^{2}}{x^{6} A^{4} 6 !}\left\{\left(\frac{b_{1}^{4}+b_{1}^{2} b_{2}^{2}+\frac{b_{2}^{4}}{7}}{A^{2}}\right) \lambda_{8}+\frac{c_{1}^{2}}{6 a_{1}^{2}}\left(3 b_{2}^{2}+10 b_{1}^{2}\right)\left(x^{2} \lambda_{4}-48 \beta \lambda_{1}\right)\right. \\
& +\frac{c_{1}^{2}}{6 a_{1}^{2}}\left(3 b_{2}^{2}+10 b_{1}^{2}-6 c_{1}^{2}\right)\left[-(1+\beta) \lambda_{8}+\left(x^{2}-\beta\right) \lambda_{5}-5\left(x^{2}+\beta\right) \lambda_{4}\right. \\
& \left.\left.-4 \beta\left(5 \lambda_{3}+15 \lambda_{2}+18 \lambda_{1}-30\right)\right]\right\},
\end{aligned}
$$

where

$$
\begin{aligned}
A^{2} & =a_{1}^{2}+a_{2}^{2}, \\
\beta & =\left(1-\alpha^{2}\right) /\left(1+\alpha^{2}\right),
\end{aligned}
$$

and all the other quantities have been previously defined. The expressions for $\lambda_{1}, \lambda_{2}, \lambda_{3}$, and $\lambda_{4}$ are given in Snow's paper ${ }^{15}$ and were reproduced for the case of maximum force in the previous paper ${ }^{16}$ by Curtis and Curtis.

If this expression for $\Delta_{6}$, together with those previously obtained for $\Delta_{2}$ and $\Delta_{4}$, be used in eq 4 , this gives the force $\mathfrak{F}(x, a)$ for any axial separation of the coils. However, in practice this separation was adjusted to give the maximum force, denoted by $\mathfrak{F}_{m}=\mathfrak{F}\left(x_{m}, \alpha\right)$, where $x_{m}=z_{m} / A$ and $z_{m}$ the separation which gives maximum force, $\mathfrak{F}_{m}$, between the actual coils, while $x_{0}=z_{0} / A$, where $z_{0}$ is the separation which gives maximum force, $F_{m}$, between two filaments. The relation between $x_{m}$ and $x_{0}$ is $x_{m}=x_{0}+\delta x_{0}$, where $\delta x_{0}$ is obtained by substituting 
in eq 16 of Snow's paper, expanding in powers of $\delta x_{0}$ and taking account of the fact that $F^{\prime \prime}\left(x_{0}, \alpha\right)=0$. It is thus found that

$$
\frac{\delta x_{0}}{x_{0}}=\frac{x_{0} \Delta_{2}^{\prime}}{\lambda_{2}}\left\{1-\Delta_{2}+\frac{\lambda_{3}}{2 \lambda_{2}}\left(\frac{x_{0} \Delta_{2}^{\prime}}{\lambda_{2}}\right)+\frac{x_{0}^{2} \Delta_{2}^{\prime \prime}}{\lambda_{2}}+\frac{\Delta_{4}}{\Delta_{2}^{\prime}}\right\}_{x=x_{0}},
$$

where primes designate derivatives with respect to $x$. In the original application contemplated, where the degree of the term was the same as its order of magnitude, a precision of the fourth order in the maximum force was obtained by taking $\delta x_{0} / x_{0}=x_{0} \Delta_{2}^{\prime} / \lambda_{2}$, which is the second degree. The additional terms in the bracket of eq 9 are now necessary, because the contributions of terms involving $b_{2}$ are larger. The order of magnitude of $\delta x_{0} / x_{0}$ is the same as before.

Applying a Taylor's expansion to the force, $\mathfrak{F}$, as a function of $x$, about the point $x_{0}$, and making use of eq 9 , the formula is obtained by which the maximum force is computed

$$
\begin{aligned}
\mathfrak{F}_{m}=n_{1} n_{2} I_{1} I_{2} F\left(x_{0}, \alpha\right)\left\{1+\Delta_{2}+\Delta_{4}+\frac{\left(x_{0} \Delta_{2}^{\prime}\right)^{2}}{2 \lambda_{2}}\right. \\
\left.+\left[\Delta_{8}+x_{0} \Delta_{4}\left(\frac{x_{0} \Delta_{2}^{\prime}}{\lambda_{2}}\right)+\frac{1}{2}\left(x_{0}^{2} \Delta_{2}^{\prime \prime}-\lambda_{2} \Delta_{2}\right)\left(\frac{x_{0} \Delta_{2}^{\prime}}{\lambda_{2}}\right)^{2}+\frac{\lambda_{3}}{6}\left(\frac{x_{0} \Delta_{2}^{\prime}}{\lambda_{2}}\right)^{3}\right]\right\}
\end{aligned}
$$

Formulas have been given (either in this or in the previous paper on the ampere) for computing all the above quantities except $\Delta_{2}^{\prime \prime}$. This is

$$
\begin{aligned}
x_{0}^{2} \Delta_{2}^{\prime \prime}= & -\frac{1}{12 x_{0}^{2}}\left\{\frac{2\left(b_{1}^{2}-c_{1}^{2}+b_{2}^{2}-c_{2}^{2}\right)}{A^{2}} \lambda_{4}+\left[\left(\frac{c_{1}^{2}}{a_{1}^{2}}+\frac{c_{2}^{2}}{a_{2}^{2}}\right) x_{0}^{2}-\left(\frac{c_{1}^{2}}{a_{1}^{2}}-\frac{c_{2}^{2}}{a_{2}^{2}}\right) \beta\right] \lambda_{3}\right. \\
& -2\left[\left(\frac{c_{1}^{2}}{a_{1}^{2}}+\frac{c_{2}^{2}}{a_{2}^{2}}\right) x_{0}^{2}+\left(\frac{c_{1}^{2}}{a_{1}^{2}}-\frac{c_{2}^{2}}{a_{2}^{2}}\right) \beta-\frac{\left(b_{1}^{2}-c_{1}^{2}+b_{2}^{2}-c_{2}^{2}\right) \lambda_{2}}{A^{2}}\right] \lambda_{2} \\
& \left.+6\left(\frac{c_{1}^{2}}{a_{1}^{2}}-\frac{c_{2}^{2}}{a_{2}^{2}}\right)\right\}
\end{aligned}
$$

The bracket of eq 10 which is added to the original formula for the force, contains only terms of sixth degree-and only those which are infinitesimals of the fourth order (considering $b_{1} / a_{1}$ and $c_{1} / a_{1}$ as infinitesimals of the first order.)

The value of $\alpha$ can be obtained more accurately by electrical measurements, than by mechanical measurements. For the electrical measurement of the ratio of the radii, the coils are mounted concentric and coplanar. Currents $I_{1}^{\prime}$ and $I_{2}^{\prime}$ in the coils are adjusted until the magnetic fields, $H_{1}$ and $H_{2}$ at the common center are equal and opposite. If $\tau=n_{2} I_{2}^{\prime} / n_{1} I_{1}^{\prime}$, when $H_{1}+H_{2}=0$, it is necessary to determine the relation between $\tau$ and $\alpha$.

For the fixed coil of rectangular section, the magnetic field, $H_{1}$, at its center is given by eq 24 of Snow's previous paper, ${ }^{17}$ when terms of sixth degree are negligible, as was the case with coils previously used and also in the present case.

This is

$$
H_{1}=\frac{2 \pi n_{1} I_{1}^{\prime}}{a_{1}}\left[1+\frac{J_{1}}{a_{1}^{2}}+\frac{G_{1}}{a_{1}^{4}}\right]
$$

17 Reference in footnote 14. 
For the solenoidal moving coil, the magnetic field, $\mathrm{H}_{2}$, at its center is given with an accuracy of 1 part in a million, provided terms of sixth degree are now retained, which gives

In eq 12 and 13

$$
H_{2}=\frac{2 \pi n_{2} I_{2}^{\prime}}{a_{2}}\left[1+\frac{J_{2}}{a_{2}^{2}}+\frac{G_{2}}{a_{2}^{4}}+\frac{K_{2}}{a_{2}^{6}}\right]
$$

$$
J_{i}=\frac{c_{i}^{2}}{3}-\frac{b_{i}^{2}}{2}, G_{i}=\frac{c_{i}^{4}}{5}-b_{i}^{2} c_{i}^{2}+\frac{3 b_{i}^{4}}{8}, \text { and } K_{i}=-\frac{5 b_{i}^{e}}{16},
$$

where the subscript $i$ may be either 1 or 2 , according as $H$ has a subscript 1 or 2 . Equating the values of $H_{1}$ and $H_{2}$, solving, and inserting the value of $\tau$

$$
\begin{aligned}
\alpha \equiv \frac{a_{2}}{a_{1}}=\tau\left\{1-\frac{1}{a_{1}^{2}}\left(J_{1}-\frac{J_{2}}{\tau^{2}}\right)+\frac{1}{a_{1}^{4}}\left[J_{1}^{2}-G_{1}\right.\right. & \left.+\frac{J_{1} J_{2}}{\tau^{2}}+\frac{G_{2}-2 J_{2}^{2}}{\tau^{4}}\right] \\
& \left.+\frac{1}{a_{1}^{6}}\left[\frac{K_{2}}{\tau^{6}}+\frac{4 J_{2}}{\tau^{2}}\left(J_{1}-\frac{J_{2}}{\tau^{2}}\right)^{2}\right]\right\}
\end{aligned}
$$

This equation gives the ratio of the radii of the centroids of the coils as a function of the ratio, $\tau$ (which is measured electrically), and of the ratios of the cross-sectional dimensions of both coils to the radius of the larger coil (which are determined from mechanical measurements).

In practice it has been found more convenient to compute a correction for each coil than to employ eq 15 . Since for any coil the formula ${ }^{18}$ for the magnetic field at its center may be written as

$$
H=\frac{2 \pi n I}{a}(1-\Delta),
$$

it follows that, for any two coaxial and concentric coils in which there are currents $I_{1}^{\prime}$ and $I_{2}^{\prime}$ such that $H_{1}+H_{2}=0$ and in which the subscript 1 is used for all the constants of the larger coil and 2 for the smaller coil.

where for each coil

$$
\alpha \equiv \frac{a_{2}}{a_{1}}=\frac{n_{2} I_{2}^{\prime}\left(1-\Delta_{2}\right)}{n_{1} I_{1}^{\prime}\left(1-\Delta_{1}\right)}
$$

$$
1-\Delta=1-\frac{b^{2}}{2 a^{2}}+\frac{c^{2}}{3 a^{2}}+\frac{3 b^{4}}{8 a^{4}}-\frac{b^{2} c^{2}}{a^{4}}+\frac{c^{4}}{5 a^{4}}-\frac{5 b^{6}}{16 a^{6}}+\ldots
$$

The last term of the series was required only for the solenoidal moving coil. Since $\Delta$ is a function of the dimensions of the coil, it is a constant that, when once computed, can be applied to any combination for measuring the ratio of the radii in which it is used.

${ }^{28}$ See p. 707 of previous paper. Reference in footnoto 1. 


\section{APPENDIX II}

\section{Correction to the Force Caused by an Axial Displacement of Some of the Turns in the Coils Made from Aluminum Ribbon}

\section{By Chester Snow}

The width, $w$, of the conducting ribbon with which the coil was wound was practically constant. The successive layers did not lie exactly one above the other, so that the axial width, $2 b$, of the coil was not the same as the width of the ribbon, and the cross section of the winding was not exactly a rectangle of the axial width, $2 b$, and the radial depth, $2 c$ (area $S=2 c w$ ), but was like that of a pack of cards which had been given a shear (nonuniform). The area, $S$, and the radial depth, $2 c$, remain unaltered.

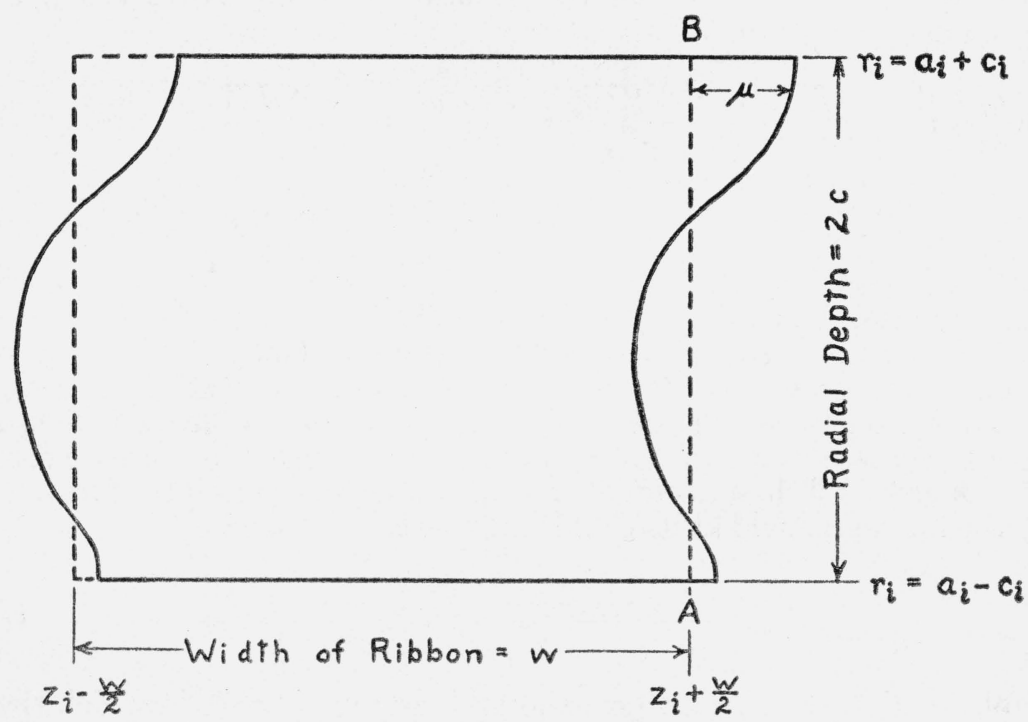

FigURE 10.-Diagram to illustrate the cross section of a coil of ribbon when the individual turns are displaced with respect to the average position.

Let $\mu$ (which is a function of $r$ ) represent the amount by which the tape at radius $r$ is displaced in the posicive $z$-direction from the position it would have if the section were rectangular. The sides, in the radial direction, of this ideal rectangle are shown as dotted lines in figure 10. The true section is shown in the figure as bounded in the radial direction by two parallel curves. The two sections have the same center of gravity $(\Sigma \mu=0)$ but do not have the same moments and products of inertia $\left(\Sigma \mu^{2} \neq 0\right.$ and $\Sigma \mu_{p} \mu_{q} \neq 0$, where $\mu_{p}$ and $\mu_{q}$ are the displacements at any two positions, $p$ and $y$ ).

The modification of the original formula for the force between coaxial coils to allow for the axial displacements of the ribbons was obtained by following through the unpublished details used in the original derivation. The following notation is the same as used in the original derivation ${ }^{19}$, where the subscript $i(=1$ or 2$)$ may refer to either of the two coils. 
The centroid of each coil section is taken as the reference point both for the calculation of maximum force $\mathfrak{F}_{m}$ between the coils and for the determination of the ratio $\alpha$ of their effective radii, so that terms of odd degree in $\mu$ do not appear in the formula. The displacement, $\mu$, is for each layer small relative to $w$, the width of the strip.

A reexamination of all the terms of the original expansion ${ }^{20}$ for determining the force between coils shows that the only modification to be made in this equation is that $b_{i}^{2}$ must be replaced ${ }^{21}$ by $\frac{w^{2}}{4}+\frac{3}{2} \bar{\mu}_{i}^{2}$, where $\bar{\mu}_{i}^{2}$ is the average of $\mu_{i}^{2}$ with respect to $r$; that is,

$$
\bar{\mu}_{i}^{2}=\frac{1}{2 c_{i}} \int_{a_{i}-c_{i}}^{a_{i}+c_{i}} \mu^{2}\left(r_{i}\right) d r_{i} \quad i=1,2 .
$$

This correction comes from an integral representing the moment of inertia of the section. Two integrals of the same order of magnitude also appear. They represent products of intertia of the form

$$
\frac{1}{S_{i}} \iint\left(r_{i}-a_{i}\right)\left(z_{i}^{\prime}-z_{i}\right) d S_{i}
$$

but are multiplied by $D_{2} F D_{a} F$, and $D_{2} F$ is zero for the maximum force, so the products of inertia are unimportant.

If $b_{i}-w_{i} / 2=\delta b_{i}$, then from the above relationship

$$
\frac{\delta b_{i}}{b_{i}}=\frac{3 \bar{\mu}_{i}^{2}}{4 b_{i}^{2}}
$$

The complete effect of this error in $b_{1}$ and $b_{2}$ cannot be found until an examination is made of the effect of these $\mu$-displacements on the magnetic field as it is related to the magnetic determination of the ratio, $\alpha$, of the radii.

On repeating the derivation of eq 24 of the previous paper for this field, $H$, no products of inertia appear, and the same change in $b$ is required as was found in the case of the formula for the force $\widetilde{F}_{m}$.

This error in $b_{1}$ and $b_{2}$ causes an error, $\delta \varlimsup_{m}$, in the final evaluation of the maximum force, $\widetilde{F}_{m}$, in two ways: first, in the force formula; second, in the ratio, $\alpha$, of the radii.

Both of these effects are taken into account in the variation formula of the previous paper. ${ }^{22}$ If the value of $\delta b_{i} / b_{i}$ from eq 20 is inserted in this formula, then

$$
\frac{\delta \mathfrak{F}_{m}}{\widetilde{F}_{m}}=\frac{-3}{8 x_{0}^{2}}\left\{\left[\left(\frac{1+\beta}{3}\right) \lambda_{2}-\beta\right] \frac{\bar{\mu}_{1}^{2}}{a_{1}^{2}}+\left[\left(\frac{1-\beta}{3}\right) \lambda_{2}+\beta\right] \frac{\bar{\mu}_{2}^{2}}{a_{2}^{2}}\right\},
$$

where $\bar{\mu}_{i}^{2}=\frac{1}{N_{i}} \sum_{n=1}^{N_{i}} \mu_{i}^{2}$, in which $\mu_{i}$ is the displacement of the $n$th turn. It is measured in the axial direction from the line $A B$ so chosen that $\sum_{n=1}^{N_{i}} \mu_{n}=0$, where $N_{i}$ is the number of turns.

20 See eq 7 of the paper referred to in footnote 19.

${ }^{21}$ An equivalent formula is given, without derivation by Rosa, Dorsey, and Miller, Bul. B8 8, 269 (1911) \$171. The formula is given on p. 316 .

22 See eq 27 of the paper referred to in footnote 19. 